\title{
1 Transit-amplifying cells coordinate changes in intestinal epithelial cell-type
}

\section{2 composition}

3 Laura E. Sanman ${ }^{1} \dagger$, Ina W. Chen ${ }^{1} \dagger$, Jake M. Bieber ${ }^{1,2}$, Veronica Steri ${ }^{3,4}$, Byron Hann ${ }^{3,4}$, Lani F.

$4 \quad \mathrm{Wu}^{1 *}$, Steven J. Altschuler ${ }^{1 *}$

$5 \quad{ }^{1}$ Department of Pharmaceutical Chemistry, University of California San Francisco, San

6 Francisco, CA 94158, USA

$7 \quad{ }^{2}$ Graduate Program in Bioengineering, University of California Berkeley, University of

8 California San Francisco, San Francisco CA 94158, USA

$9{ }^{3}$ Helen Diller Family Comprehensive Cancer Center, University of California, San Francisco,

10 San Francisco, CA 94158, USA.

$11{ }^{4}$ Preclinical Therapeutics Core, University of California, San Francisco, San Francisco, CA

1294158, USA.

13 *Correspondence to: lani.wu@ucsf.edu, steven.altschuler@ucsf.edu

$14 \dagger$ Equal contributions

15

16

17

18

19

20

21 


\section{Abstract}

23 Renewing tissues have the remarkable ability to continually produce both proliferative progenitor

24 and specialized differentiated cell-types. How are complex milieus of microenvironmental signals

25 interpreted to coordinate tissue cell-type composition? Here, we develop a high-throughput

26 approach that combines organoid technology and quantitative imaging to address this question in

27 the context of the intestinal epithelium. Using this approach, we comprehensively survey enteroid

28 responses to individual and paired perturbations to eight epithelial signaling pathways. We uncover

29 culture conditions that enrich for specific cell-types, including $\operatorname{Lgr}^{+}$stem and enteroendocrine

30 cells. We analyze interactions between perturbations and dissect mechanisms underlying an

31 unexpected mutual antagonism between EGFR and IL-4 signals. Finally, we show that, across

32 diverse perturbations, modulating proliferation of transit-amplifying cells also consistently

33 changes the composition of differentiated secretory and absorptive cell-types. This property is

34 conserved in vivo and can arise from differential amplification of secretory and absorptive

35 progenitor cells. Taken together, the observations highlight an underappreciated role for transit-

36 amplifying cells in which proliferation of these short-lived progenitors provides a lineage-based

37 mechanism for tuning differentiated cell-type composition. 


\section{Introduction}

46 A central question in the study of complex tissues is how diverse signals are integrated to regulate

47 cell-type composition. Dissection of mechanisms underlying the mapping from signals to tissue

48 composition is complicated by the heterogeneous makeup of interconnected cell-types, which

49 exert influences upon one another through the lineage structure and cell-cell interactions. Further,

50 most studies focus on the effects of individual signals on individual cell-types, due to a lack of

51 methods that enable systematic identification of signal integration mechanisms. What are the

52 tissue-wide effects of common microenvironmental signals on cell-type composition? How do

53 multiple signals modify each other's effects? Finally, are there intrinsic tissue properties that shape

54 response to diverse signals?

55 Here, we address these questions in the context of the intestinal epithelium, a model renewing

56 tissue (Beumer \& Clevers, 2016; Cheng \& Leblond, 1974b; A. Tian et al., 2016). The intestinal

57 epithelium is particularly remarkable in that it maintains a stereotypic tissue composition despite

58 a rapid 3- to 5-day turnover. During renewal of the intestinal epithelium, gr5 $^{+}$crypt-base stem

59 cells differentiate into proliferating transit-amplifying (TA) progenitors, which in turn adopt

60 absorptive (enterocyte) or secretory (Paneth, goblet, enteroendocrine (EE)) cell fates (Cheng \&

61 Leblond, 1974b) (Figure 1A). The confluence of proliferating and differentiation decision

62 processes establishes tissue composition, which guides overall tissue function. Though much

63 progress has been made in defining the 'parts list' of factors that guide intestinal epithelial renewal

64 (Clevers, 2013; Flier et al., 2009; Yin et al., 2014a), it is unclear how these factors are integrated

65 by the tissue during maintenance and in response to perturbations. 
66 To quantitatively measure intestinal epithelial cell-type composition and study its changes in

67 response to microenvironmental signals, we utilized a recently established enteroid monolayer

68 culture system that recapitulates key features of the intestinal epithelium (Thorne et al., 2018).

69 Enteroid monolayer cultures maintain characteristics of intestinal epithelial architecture, including

70 organization into crypt- and villus-like compartments and apical-basolateral polarization.

71 Importantly, these cultures also preserve core tissue processes ex vivo, generating all major

72 intestinal epithelial cell-types ( $\operatorname{Lgr} 5^{+}$stem, TA, and differentiated secretory and absorptive cells)

73 with a turn-over rate similar to the in vivo renewal rate. Crucially, due to their 2D nature, enteroid

74 monolayer cultures are amenable to high-throughput screening of perturbations in microwell

75 format. In this work, enteroid monolayers are used as a primary platform for hypothesis generation

76 with key observations further evaluated in 3D organoids and in vivo.

77 Here, we present a systems approach for investigating signal integration and lineage processes in

78 the intestinal epithelium. We first expanded the capabilities of the enteroid monolayer platform to

79 monitor and quantify major intestinal epithelial cell-types, such as stem, TA, and differentiated

80 cell-types, in a robust and automated manner. This enabled confirmation of relevant stem and TA

81 functions, such as proliferation and production of differentiated cell-types, in enteroid monolayer

82 cultures. We then combined enteroid culture with high-throughput combinatorial perturbations to

83 profile responses to a diverse set of treatment conditions. Analysis of tissue response profiles

84 identified conditions that enrich for specific intestinal epithelial cell-types and revealed

85 interactions in the integration of perturbations. Finally, studies using enteroid monolayers, 3D

86 organoids, and mice uncovered a global trend in how intestinal epithelial cell-type composition

87 changes in response to perturbations; specifically, a link between TA proliferation and secretory

88 cell composition. Based on experimental observations and mathematical modeling, we propose a 
89 model of intestinal epithelial lineage control in which differential amplification of TA progenitors

90 allows the balance of secretory to absorptive cell lineages to be regulated through TA proliferation.

\section{Results}

\section{A quantitative microscopy platform to study regulation of intestinal cell-type composition}

93 As an experimental model for the study of intestinal epithelial cell-type composition in high-

94 throughput, enteroid monolayers should be quantifiable, reproducible, and faithfully recapitulate

95 relevant in vivo tissue properties. Here, we develop and test these features of the enteroid

96 monolayer platform.

97 To measure intestinal epithelial composition in high-throughput, we established a computational

98 pipeline to automatically quantify major intestinal cell-types from images of enteroid monolayers

99 (Figure 1B). Specifically, we developed algorithms to detect cells expressing markers for stem

$100\left(\mathrm{Lgr}^{+}\right)$, proliferating $\left(\mathrm{EdU}^{+}\right)$, Paneth $\left(\mathrm{Lyz}^{+}\right)$, goblet $\left(\mathrm{Muc}^{+}\right)$, and enteroendocrine $\left(\mathrm{EE}\right.$; ChgA $\left.{ }^{+}\right)$

101 cells as well as identifying cell nuclei (Hoechst) (Figure 1-Supplement 1, Materials and Methods).

102 Enterocytes were not directly quantified because we were not able to identify a reliable antibody

103 to specifically label this population in immunofluorescence assays. Thus, our studies of

104 differentiated cell-types were limited to the secretory lineage. When evaluated against expert

105 manual counting, the algorithms exhibited high quantification accuracy across the cell-types

106 measured (Table 1).

107 To evaluate reproducibility, cell-type measurements were quantified across replicate wells. A crypt

108 seeding density (10-20\% initial confluency) was identified where there was no relationship 109 between initial seeding density and cell-type composition after 48 hours of culture. In this regime, 
there was also relatively low inter-replicate variability in cell-type numbers. (Figure 1-Supplement

2).

To assess recapitulation of relevant in vivo intestinal epithelial properties, we examined cell-type composition and progenitor cell functions including proliferation and differentiation. We first observed that jejunal enteroid monolayers exhibited cell-type composition comparable to the composition of in vivo jejunal epithelium (Table 2). We then confirmed that enteroid monolayers recapitulate progenitor proliferation and production of differentiated cell-types. By labeling

117 cycling cells with EdU upon initial plating, we observed that the initial population of $\sim 25 \%$ 118 proliferative $\left(\mathrm{EdU}^{+}\right)$cells produce the vast majority $(\sim 80 \%)$ of cells in enteroid monolayers after 11948 hours of culture (Figure 1C). This indicated that the majority of quantified cells after 48 hours 120 of culture were produced by initial progenitors. Further, we observed $\mathrm{EdU}^{+}$cells that colocalized 121 with markers of Paneth (Lyz), goblet (Muc2), and EE (ChgA) cells, indicating that progenitor cells 122 produce major differentiated cell-types over the 48-hour culture period (Figure 1D).

123 Taken together, enteroid monolayers preserve important characteristics of the intestinal epithelium 124 ex vivo, such as cell-type composition and production of differentiated cell-types. Enteroid 125 monolayers also demonstrate reproducible outgrowth and low replicate variance. Thus, enteroid 126 monolayers constitute a robust platform for capturing tissue-wide responses to perturbations and

127 for generating hypotheses on control of intestinal epithelial cell-type composition.

128 Systematic survey of cell-type composition changes in response to single and pairwise 129 signaling modulators

130 To map a wide range of tissue composition phenotypes, 13 epithelial-intrinsic and

131 microenvironmental modulators that target eight core intestinal epithelial signaling pathways 132 (Wnt, BMP, Notch, HDAC, JAK, p38MAPK, TGF-beta, EGFR (Basak et al., 2017a; Batlle et al., 
133 2002; Mathieu Houde et al., 2001; Richmond et al., 2018a; Rodríguez-Colman et al., 2017; van

134 der Flier \& Clevers, 2009; Yin et al., 2014b)) and are known to have diverse effects on tissue cell-

135 type composition were selected (Table 3). In previous reports, combinations of perturbations have

136 been shown to be more effective than single perturbations in enriching particular cell-types (Basak

137 et al., 2017a; Yin et al., 2014b). Thus, to survey a broad range of tissue states, modulators were

138 applied to enteroid monolayers individually (13 conditions) and in all possible pairwise

139 combinations (78 conditions) (workflow: Figure 2-Supplement 1A). Perturbation concentrations

140 were guided by literature reports and confirmed with dose-response experiments (Table 3, Figure

141 2-Supplement 1B) (Basak et al., 2017a; von Moltke et al., 2015; Yin et al., 2014b).

142 We then sought to combine cell-type number measurements into readouts that reflect changes in

143 important aspects of intestinal epithelial cell-type composition. Changes in overall tissue

144 composition can be attributed to a number of changes in underlying cell-type populations. For

145 instance, an overall decrease in the fraction of a specific cell-type, such as goblet cells, may be

146 caused by an increase in the number of progenitors (or other cell-types), a decrease in the secretory

147 fraction in the differentiated cell population, or a decrease in goblet cells within the secretory cell

148 lineage. To distinguish between these different possibilities, we designed features that measured

149 the size of the progenitor population as well as the relative composition of cells in the differentiated

150 population, as follows.

151 To quantify changes in the progenitor cell populations, we measured the absolute numbers of

152 proliferating stem $\left(\mathrm{EdU}^{+} \mathrm{Lgr5}^{+}\right)$and TA (EdU $\left.{ }^{+} \mathrm{Lgr5}^{-}\right)$cells (Figure 2A, Figure 2-Supplement 2A).

153 Since specific TA markers are lacking, TA cells were defined as non-stem proliferating cells. To

154 quantify changes in the relative makeup of the differentiated population, we designed fractional

155 readouts that reflect changes in two differentiation branching points: the secretory-absorptive 
branch point, and the secretory cell-type branch point. To capture secretory vs. absorptive lineage

157 biases, we computed the fraction of differentiated ( $\left.\mathrm{Lgr}^{-} \mathrm{EdU}^{-}\right)$cells that express secretory

158 (Paneth+goblet+EE) markers (\#secretory/\#diff) (Figure 2A, Figure 2-Supplement 2B). The sum

159 of Paneth, goblet, and EE cells is a reasonable approximation for the number of secretory cells as

160 these cell-types make up the majority of secretory cells (Cheng \& Leblond, 1974b; Haber et al.,

161 2017). Finally, to capture biases towards different cell-types within the secretory lineages, we

162 computed the specific fractions of all secretory cells positive for Paneth (Lyz), goblet (Muc2), and

163 EE (ChgA) cell markers (\#Paneth/\#secretory, \#goblet/\#secretory, \#EE/\#secretory) (Figure 2A,

164 Figure 2-Supplement 2C).

After treatment with established modulators of cell-type composition (GSK3-i+HDAC-i, Notch-i,

IL-4, EGFR-i, PORCN-i), changes in enteroid monolayer cell-type readouts were in agreement

167 with previous 3D organoid and in vivo studies (Basak et al., 2017a; Beumer \& Clevers, 2016; Qi

168 et al., 2017; van Es et al., 2005; von Moltke et al., 2015; Yin et al., 2014b) (Figure 2-Supplement

$1693 \mathrm{~A}$, Table 3). Changes in the prevalence of each cell-type were also confirmed at the RNA level

170 using quantitative reverse transcription PCR (qRT-PCR; Figure 2-Supplement 3B).

\section{Identification of conditions that enrich for $\operatorname{Lgr5}^{+}$stem and EE cells}

172 Single and pairwise perturbation effects on intestinal epithelial cell-type composition (546

173 measurements $=91$ conditions $\times 6$ cell-type readouts) were measured (Figure 2B). The vast

174 majority of measurements were previously uncharacterized, with a number of conditions strongly

175 modulating different aspects of tissue composition (Table 4). Below, we highlight conditions that 176 were previously unknown to enrich for stem and EE cells.

177 Pairwise combinations of inhibitors of GSK3, p38MAPK, BMPR, HDAC, and JAK1/2 increased 178 the number of $\mathrm{Lgr}^{+}$stem cells (Figure 2B, bottom callout 1). Notably, these conditions caused 
179 similar, if not increased, enrichment for $\operatorname{Lgr}^{+}$stem cells compared to the current benchmark condition (GSK3 inhibitor + HDAC inhibitor (Yin et al., 2014a)). Lgr5 $5^{+}$stem cell enrichment was

181 also observed at the RNA level, as indicated by qRT-PCR analysis of Lgr5 RNA (Figure 2C).

182 Since JAK1/2 had not been connected with stemness in the mammalian intestinal epithelium in

183 the absence of inflammation (Richmond et al., 2018b), we repeated the GSK3-i and JAK1/2-i

184 treatment in 3D organoids and again observed expansion of the $\mathrm{Lgr}^{+}$stem cell population (Figure 185 2D).

186 Conditions were also identified that selectively enrich for EE cells relative to other secretory cell187 types (Table 4). The condition that most strongly enriched for EE cells was the combination of 188 TGF-beta and PORCN inhibitor (Figure 2B, bottom callout 2). TGF-beta and PORCN inhibitor 189 treatment of enteroid monolayers also caused an increase in RNA levels of the EE marker ChgA 190 relative to RNA levels of markers of other secretory cell-types (Figure 2E). Since a connection

191 between TGF-beta signaling and EE cell regulation had not been previously established, we 192 applied the treatment to 3D organoids and again observed EE enrichment (Figure 2F).

\section{Interaction mapping reveals mutual antagonism between IL-4 and EGFR-i}

194 After analyzing perturbations effects individually, we next examined how pairs of perturbations

195 interact to modulate cell-type composition. A commonly used framework for identifying 196 perturbation interactions is a multiplicative model, where the combined effect of two non197 interacting perturbations is expected to be the product of the effects of individual perturbations 198 (Dixon et al., 2009). For each cell-type composition readout, we analytically defined an interaction 199 between any pair of perturbations as a combinatorial perturbation effect that deviated strongly 200 (effect size $>5$ ) from the expectation of the multiplicative model. (The multiplicative model was 201 chosen due to its interpretability and fit to the data; Figure 3-Supplement 1, Materials and 
Methods). Biologically, interactions were interpreted as direct or indirect connections between the perturbed signaling pathways (Coster et al., 2017; Papin et al., 2005). The majority of perturbation pairs showed little deviation from the multiplicative model expectation (Figure 3-Supplement 1A). Interestingly, perturbation interactions were predominantly observed in the regulation of EdU stem and TA cell numbers, as compared to the regulation of secretory, goblet, Paneth, or EE cell prevalence (Figure 3A).

In some cases, identified interactions reflected known pathway biology, such as interactions between perturbations that modulate the same signaling pathway (e.g. the synergistic effect of

210 Wnt3a and GSK3-i, Figure 3-Supplement 2). Other cases were less expected and suggest novel

211 interactions in the regulation of specific cell-types. One particularly unexpected example is the 212 interaction between IL-4 and EGFR-i in regulating TA cells. IL-4 and EGFR-i are not known to 213 interact or utilize a shared signaling pathway and, interestingly, appeared mutually antagonistic in

214 combination. When either IL-4 or EGFR-i was applied singly, the number of TA cells was reduced 215 by $\sim 4$ and $\sim 6$ log-fold relative to control, respectively. However, when IL-4 and EGFR-i were 216 applied in combination, the number of TA cells was reduced by only $\sim 1.5$ log-fold relative to 217 control (Figure 3B).

218 We investigated potential mechanisms for the observed mutual antagonism of IL-4 and EGFR-i.

219 EGFR-i treatment decreases proliferation by reducing MEK-Erk activity (Basak et al., 2017a).

220 However, IL-4 treatment resulted in Erk activation (as measured by phospho-Erk nuclear 221 translocation) even in the context of EGFR inhibition (Figure 3C). This suggested that IL-4 222 antagonized the effects of EGFR-i by bypassing EGFR-i to activate Erk. When IL-4 and EGFR-i 223 were applied in the context of MEK inhibition (which is upstream of Erk), IL-4 did not antagonize 224 the effects of EGFR-i on TA cell numbers (Figure 3-Supplement 3A) or induce phospho-Erk 
nuclear translocation (Figure 3-Supplement 3B). This indicated that IL-4 activates MEK-Erk

228 (Goldman et al., 2009)) production by the tissue (Figure 3D). The addition of a BMP receptor inhibitor, BMPR-i, rescued the IL-4-induced decrease in transit-amplifying cell numbers further confirming BMP secretion as the mechanism by which IL-4 dampens proliferation (Figure 3-

231 Supplement 4A,B). EGFR-i reduces BMP2 production induced by IL-4 treatment, suggesting a 232 mechanism by which EGFR-i antagonizes the effects of IL-4 (Figure 3E).

233 In summary, analysis of perturbation interactions, which occurred predominantly in progenitor 234 cells, revealed a surprising mutual antagonism between IL-4 and EGFR signaling in the regulation 235 of TA cells. Mechanistic investigation revealed that the mutual antagonism arises from IL-4 236 bypassing EGFR-i-induced blockade of MEK-Erk-driven cell cycle progression and EGFR-i

237 blocking IL-4-induced production of antiproliferative BMP2.

\section{Modulating transit-amplifying cell proliferation alters secretory cell-type composition} dataset to survey global trends in how intestinal epithelial cell-type composition changes in

241 response to perturbations. In particular, the observation of increased interaction in regulation of

242 the progenitor populations led us to investigate how changes in progenitor cell numbers relate to 243 changes in the composition of differentiated cell-types. Despite the diversity of perturbation

244 mechanisms, we observed a surprising trend: the numbers of transit-amplifying cells negatively 245 correlated with the fraction of differentiated cells that express secretory markers (Figure 4A) as 246 well as with the fraction of secretory cells that express the EE marker (Figure 4-Supplement 1A).

247 In contrast, little-to-no correlation was observed between the number of proliferating $\operatorname{Lgr}^{+}$stem 
248 cells and differentiated cell-type composition (Figure 4A, Figure 4-Supplement 1A), indicating

249 that the trend was specific for TA cells. To assess whether the cell-type correlations were driven

250 by any individual perturbation, perturbations were dropped one at a time from the dataset

251 (dropping all single and pairwise conditions containing the perturbation) and correlations were re-

252 calculated for each data subset. We found that dropping EGFR-i from the dataset largely abrogated

253 the anticorrelation between TA number and EE fraction (Figure 4-Supplement 1B, red arrowhead),

254 which is consistent with recent work suggesting that EE cell production can be triggered by EGFR-

255 i-induced stem cell quiescence (Basak et al., 2017a). However, the anticorrelation between TA

256 number and secretory fraction is not driven by a specific perturbation (Figure 4B), possibly

257 indicating a tissue-intrinsic property.

258 We further investigated the anticorrelation between TA numbers and secretory cell fraction in

259 enteroid monolayers, 3D organoids, and in vivo. To test whether the correlation is driven by TA

260 proliferation, we directly modulated proliferation in enteroid monolayers using Cdk and Aurora

261 kinase inhibitors and found that inhibiting proliferation, which decreases TA numbers, caused an

262 increase in secretory cell fractions (Figure 4C). Further, CDK4/6 inhibition increased the secretory

263 cell fraction (and decreased TA cell numbers) in a dose-dependent manner (Figure 4-Supplement

264 2). We then used $3 \mathrm{D}$ organoids to demonstrate that the correlation was specific to TA, and not

265 stem cells. 3D organoid cultures were first enriched for either stem (treatment with GSK3-

266 i+HDAC-i (Yin et al., 2014b)) or TA (treatment with PORCN-i) cells. qRT-PCR analysis

267 confirmed enrichment for Lgr5 RNA over Ki67 RNA in GSK3-i+HDAC-i-treated 3D organoids,

268 and Ki67 RNA over Lgr5 RNA in PORCN-i-treated 3D organoids (Figure 4-Supplement 3). IF

269 staining also showed almost complete conversion to $\mathrm{Lgr}^{+}$stem cells in GSK3-i+HDAC-i-treated

$2703 \mathrm{D}$ organoids, while PORCN-i-treated 3D organoids retained proliferating $\left(\mathrm{EdU}^{+}\right)$cells but lost 
271 Lgr5 $^{+}$stem cells (Figure 4D, images). Organoids were then removed from enrichment media and

272 treated with the CDK4/6 inhibitor palbociclib, which significantly impairs proliferation in 3D

273 intestinal organoids (Basak et al., 2017b). Atoh1 and Hes1 RNA levels were measured by qRT-

274 PCR to quantify changes in secretory and absorptive cell fractions, respectively. Strikingly,

275 CDK4/6 inhibition increased the ratio of Atoh1/Hes1 RNA in 3D organoids enriched for TA cells.

276 However, CDK4/6 inhibition had a reduced effect on 3D organoids enriched for gr $^{+}$stem cells $^{2}$

277 (Figure 4D, graphs). These data indicate that proliferation of TA cells drives the observed changes

278 in secretory prevalence. Lastly, we validated the correlation between TA proliferation and

279 secretory fraction in vivo. Mice ( $\mathrm{n}=8$ per group) were treated with the CDK4/6 inhibitor palbociclib

280 or vehicle. After 50 hours of treatment, intestinal crypts were harvested and gene expression was

281 measured by qRT-PCR. CDK4/6-i treatment decreased Ki67 expression, indicating the treatment

282 effectively decreased proliferation (Figure 4-Supplement 4A). Importantly, CDK4/6-i treatment

283 increased the Atoh1/Hes 1 ratio (Figure 4E) and, to a lesser extent, the Dll/Notch ratio (Figure 4-

284 Supplement 4B), demonstrating that proliferation is anti-correlated with secretory fraction in vivo.

\section{Differential amplification as a model for proliferation-based control of tissue composition}

286 How does altering TA cell proliferation affect the abundance of secretory cells relative to other

287 differentiated (absorptive) cell-types? Previous studies suggest that secretory progenitors are less

288 proliferative compared to absorptive progenitors. In particular, commitment to a secretory fate

289 (specifically expression of the Notch ligand D111) has been observed to coincide with cell cycle

290 exit (Stamataki et al., 2011), and lineage tracing experiments found that secretory cell clones are

291 on average smaller than absorptive cell clones (Bjerknes \& Cheng, 1999). To experimentally

292 confirm that secretory progenitors indeed undergo fewer divisions than absorptive progenitors, an

293 EdU dilution experiment was conducted. A pulse of EdU was administered for the first 9 hours of 
294 culture (less than one TA cell cycle length (Matsu-Ura et al., 2016)), followed by a chase of 39

295 hours (Figure 5A). EdU is initially incorporated into proliferating cells and then subsequently

296 diluted with each cell division. Thus, EdU intensity in differentiated cells serves as a proxy for

297 division number. Cells were fixed and stained for secretory cell markers Lyz, Muc2, and ChgA as

298 well as EdU. EdU intensity distribution for all labeled cells was bimodal, indicating presence of

299 two distinct subpopulations with one population of cells dividing fewer times (higher EdU

300 intensity) than the other population (lower EdU intensity, Figure 5A). The EdU intensity

301 distributions for $\mathrm{Lyz}^{+}$Paneth, $\mathrm{Muc}^{+}$goblet, and $\mathrm{ChgA}^{+} \mathrm{EE}$ cells were clearly shifted right

302 (towards higher EdU intensity) compared to all epithelial cells, indicating that secretory cells

303 divided fewer times compared to the overall population of intestinal epithelial cells (Figure 5A).

304 To mathematically evaluate whether differential amplification of secretory and absorptive

305 progenitors could explain the observed anti-correlation between TA proliferation and secretory

306 cell abundance, a simple exponential growth model was established. We computed the expected

307 number of differentiated progeny cells from progenitor (TA) cells committed to either secretory

308 fates or absorptive fates. The ratio of the expected output from secretory progenitors to that from

309 absorptive progenitors captures the relative prevalence of secretory to absorptive cells in the

310 differentiated population (Materials and Methods). To test how the relative difference in secretory

311 and absorptive progenitor division numbers impacts the relationship between proliferation rate and

312 tissue composition, we scanned through different division rates — and thus division numbers- for

313 secretory and absorptive progenitors. We found that only parameter regimes where secretory

314 progenitors divide fewer times than absorptive progenitors recapitulated the observed anti-

315 correlation between proliferation and the ratio of secretory to absorptive cells (Figure 5B-C, Figure 
5-Supplement 1). Thus, differential amplification of TA progenitors in the intestinal epithelium

317 could provide a mechanism for controlling secretory-absorptive bias through proliferation.

\section{Discussion}

319 How the intestinal epithelium globally integrates microenvironmental signals to regulate tissue

320 composition has been challenging to study due to a lack of quantitative, high-throughput methods.

321 Here, we developed a platform utilizing enteroid monolayers to comprehensively survey changes

322 in intestinal epithelial cell-type composition to diverse perturbations. This enabled the

323 identification of new culture conditions that enrich for specific cell-types, the dissection of

324 perturbations that have unexpected combined effects on tissue growth, and the discovery that

325 differential amplification of progenitor cells in different lineages can control differentiated cell-

326 type composition. Importantly, recapitulation of perturbation effects and the proliferation-

327 secretory link in both 3D organoids and in vivo lends support to the hypothesis generation ability

328 of enteroid monolayers.

329 In terms of specific culture conditions, it was observed that pairwise combinations of GSK3,

$330 \mathrm{JAK} 1 / 2, \mathrm{HDAC}, \mathrm{BMPR}$, and p38 MAPK inhibitors enriched for $\mathrm{Lgr5}^{+}$stem cells. JAK1/2

331 inhibition has not been connected with regulation of stem cells under non-inflammatory

332 conditions. Intriguingly, during inflammation JAK $1 / 2$ is essential for reserve stem cell activation

333 (Richmond et al., 2018a). Since JAK1/2 inhibition increased Lgr5 ${ }^{+}$stem cell numbers, this could

334 indicate a difference in the regulation of homeostatic $\left(\mathrm{Lgr}^{+}\right)$and reserve stem cells. In addition,

335 it was observed that combined TGF-beta stimulation and PORCN inhibition increases the fraction

336 of enteroendocrine cells in the secretory lineage. TGF-beta signaling increases and Wnt signaling

337 decreases as cells migrate up the crypt-villus axis (Barnard et al., 1989; Farin et al., 2016). 
338 Therefore, these data suggest a connection between spatial locations on the crypt-villus axis and 339 differentiated cell-type composition.

340 By analyzing combinations of microenvironmental factors, we found more interactions amongst

341 signals regulating progenitor (stem and TA) cell numbers than prevalence of differentiated cell-

342 types. Possible reasons for the increased number of interactions include that either more signals

343 control progenitor proliferation, or that signals act redundantly upon a smaller number of shared

344 pathways. By examining specific pathway interactions, we found an unexpected mutual

345 antagonism between IL-4 and EGFR-i that regulated the TA cell population. It was previously

346 unknown that IL-4 induces BMP production, which has implications for its effects on the intestinal

347 epithelium during type 2 immune responses such as worm infection (von Moltke et al., 2015).

348 Further, it is surprising that IL-4 can bypass EGFR blockade, given recent data suggesting that

349 EGFR is a gatekeeper of MEK-Erk-driven cell cycling in the intestinal epithelium (Basak et al., $350 \quad 2017 a)$.

351 Lastly, our finding that perturbing TA cell proliferation altered the balance of secretory and

352 absorptive differentiated cell-types underpins a new perspective on the role of the intestinal lineage

353 structure in regulating cell-type composition of tissues. Lineage structures have been modeled in

354 the past, such as the branching of progenitors in enabling robust feedback control (Lander et al.,

355 2009). Here, we find that a differential amplification model of transit-amplifying progenitors in

356 different lineages allows for control of tissue cell-type composition through modulation of

357 proliferation. This model can be contrasted with a probabilistic stem cell decision model, in which

358 cell-type composition is determined by stochastic decision-making in stem cells (Balázsi et al.,

359 2011). We do not rule out that probabilistic fate decisions may still play an important role. 
360 However, the current study provides evidence that differential amplification of progenitors makes

361 a significant contribution in shaping the tissue composition.

362 The link between TA proliferation and differentiated cell-type composition, as well as the

363 observation of increased perturbation interactions in regulation of TA cells, point to a crucial and

364 currently overlooked role for these short-lived progenitor cells in guiding tissue function. The

365 intestinal epithelium, like many actively renewing tissues, is generated by stem cells that

366 differentiate into short-lived progenitors, such as TA cells, and then assume differentiated cell

367 fates. Intriguingly, many tissues, including skin and the hematopoietic system, feature transit-

368 amplifying cells as intermediates between the stem and differentiated cell populations. By

369 separately processing signals, these short-lived progenitor cell populations may broadly serve as a

370 buffer that enables coordinated tissue responses to changing microenvironments (e.g. worm

371 infections (Birchenough et al., 2016)) while insulating the stem cell population from extreme,

372 transient changes. 


\section{Materials and Methods}

374

$\underline{\text { Mice }}$

375 All animal care and experimentation was conducted under protocol AN-179937 agreed upon by

376 the Administrative Panel on Laboratory Animal Care at the University of California, San

377 Francisco. All our animal studies are performed in full accordance with UCSF Institutional

378 Animal Care and Use Committee (IACUC). 5- to 6-week-old male C57BL/6 mice

379 (C57BL/6NHsd) were purchased from Harlan and housed with ad libitum food and water on a

$38012 \mathrm{hr}$ light cycle at the UCSF Preclinical Therapeutics Core vivarium.

$\underline{\text { Media }}$

383 Organoid basal media (OBM) consists of Advanced DMEM/F12 with non-essential amino acids 384 and sodium pyruvate (Fisher Scientific \#12634-028) containing 1x N-2 (Fisher Scientific 385 \#17502-048), 1x B-27 (Invitrogen \#17504-044), 10 mM HEPES (Invitrogen \#15630080), 1x 386 GlutaMAX (Invitrogen \#35050-061), $1 \mu \mathrm{M}$ N-acetylcysteine (Sigma Aldrich \#A9165), 100 $387 \mathrm{U} / \mathrm{mL}$ penicillin and $100 \mu \mathrm{g} / \mathrm{mL}$ streptomycin (Corning \#30-002).

388 For initial seeding, enteroid monolayers were maintained in OBM supplemented with $3 \mu \mathrm{M}$ 389 CHIR-99021 (Sigma Aldrich \#SML1046), 50 ng/mL murine EGF (Invitrogen \#PMG8043), 1 $390 \mu \mathrm{M}$ LDN-193189 (Sigma Aldrich \#SML0559), 500 ng/mL murine R-spondin-1 (Peprotech 391 \#315-32), and $10 \mu \mathrm{M}$ Y-27632 (Selleck Chemicals \#S1049).

3924 hours after initial seeding, media was changed into OBM supplemented with $50 \mathrm{ng} / \mathrm{mL}$ murine 393 EGF, $100 \mathrm{ng} / \mathrm{mL}$ murine Noggin, and $500 \mathrm{ng} / \mathrm{mL}$ murine R-spondin-1. Perturbations applied in 394 the studies described here were all applied in the background of this medium.

Enteroid monolayer cultures

397 Enteroid monolayers were derived as previously described (Thorne et al., 2018). Briefly, 398 jejunum was isolated from male mice between 6-12 weeks of age. Mice used were either from 399 the C57BL/6 strain or, when indicated, the Lgr5 ${ }^{\text {eGFP-DTR }}$ strain (H. Tian et al., 2011) (kind gift of 400 Frederic de Sauvage, Genentech via Ophir Klein under MTA \#OM-216813). Epithelium was 401 released from jejunal tissue by incubation in ice-cold PBS with 3 mM EDTA in PBS (Ambion 402 \#9260). Released epithelial tissue was washed 3x with OBM, after which crypts were separated 403 from villus material using 100 and $70 \mu \mathrm{m}$ cell strainers (BD Falcon) in succession. Crypts were 
resuspended in seeding media and plated on Matrigel (Thermo Fisher \#CB-40234C)-coated 96well optical bottom plates (BD Biosciences \#353219 and Greiner \#655090). Typically, 300 crypts were seeded per well. We identified this seeding density because, at this density, we did not observe an effect of variations in initial confluency on cell outgrowth (\#cells) or cell-type composition (Figure 1-Supplement 2). Four hours after seeding, cells were washed with OBM and incubated in control media containing other perturbations of interest.

$4113 \mathrm{D}$ organoid cultures

412 3D organoids were cultured as previously described (Sato et al., 2009). For imaging experiments,

413 3D organoids were seeded in $10 \mu \mathrm{L}$ of Matrigel in 96-well optical bottom plates.

415 CDK4/6-i administration to mice and tissue harvest

416 To test the effects of cell cycle inhibition on the secretory:absorptive ratio, palbociclib (LC

417 Laboratories \#P-7744) at $150 \mathrm{mg} / \mathrm{kg}$ in $50 \mathrm{mM}$ sodium lactate buffer $\mathrm{pH} 4.4$ was administered to

418 mice by oral gavage every 24 hours for 48 hours (at 0 hours, 24 hours, and 48 hours). At 50

419 hours, the small intestine was harvested and intestinal crypts were harvested as described in the

420 enteroid monolayer culture section above. Crypts were lysed in Buffer RLT (RNEasy Kit,

421 Qiagen) for subsequent RNA purification.

423 Growth factors and chemical compounds

424 All growth factors and chemical compounds were purchased from suppliers and used as

425 designated without further purification. Unless otherwise indicated, perturbations were used as

426 follows:

\begin{tabular}{|c|c|c|}
\hline Perturbation & Vendor and Catalog \# & Concentration \\
\hline DAPT (Notch-i) & Stemgent \#04-0041 & $10 \mu \mathrm{M}$ \\
\hline CHIR-99021 (GSK3-i) & Sigma Aldrich \#1046 & $3 \mu \mathrm{M}$ \\
\hline Valproic acid (HDAC-i) & Sigma Aldrich \#P4543 & $1 \mathrm{mM}$ \\
\hline IWP-2 (PORCN-i) & Selleck Chemicals \#S7085 & $2 \mu \mathrm{M}$ \\
\hline
\end{tabular}




\begin{tabular}{|c|c|c|}
\hline Wnt3a & R\&D Systems \#5036-WN-500 & $200 \mathrm{ng} / \mathrm{mL}$ \\
\hline TGF- $\beta$ & PeproTech \#100-21C & $4 \mathrm{ng} / \mathrm{mL}$ \\
\hline EW-7197 (TGF- $\beta R-i)$ & Selleck Chemicals \#S7530 & $1 \mu \mathrm{M}$ \\
\hline BMP4 & R\&D Systems \#314-BP-010 & $200 \mathrm{ng} / \mathrm{mL}$ \\
\hline LDN-193189 (BMPR-i) & Sigma Aldrich \#SML0559 & $1 \mu \mathrm{M}$ \\
\hline Baricitinib (JAK1/2-i) & Selleck Chemicals \#S2851 & $2 \mu \mathrm{M}$ \\
\hline SB202190 (p38MAPK-i) & Sigma Aldrich \#S7067 & $10 \mu \mathrm{M}$ \\
\hline IL-4 & PeproTech \#214-14 & $20 \mathrm{ng} / \mathrm{mL}$ \\
\hline Erlotinib HCl (EGFR-i) & Selleck Chemicals \#S1023 & $2.5 \mu \mathrm{M}$ \\
\hline PD0325901 (MEK-i) & Selleck Chemicals \#S1036 & $1 \mu \mathrm{M}$ \\
\hline Palbociclib (PD-0332991) (CDK4/6-i) & $\begin{array}{l}\text { Selleck Chemicals \#S1116 } \\
\text { (organoid studies) or } \\
\text { LC Laboratories \#-7744 } \\
\text { (in vivo studies) }\end{array}$ & $10 \mu \mathrm{M}$ \\
\hline Flavopiridol (CDK-i) & Selleck Chemicals \#S2679 & $0.3 \mu \mathrm{M}$ \\
\hline AT9283 (AuroraK-i) & Selleck Chemicals \#S1134 & $1 \mu \mathrm{M}$ \\
\hline
\end{tabular}

428 Immunofluorescence assay

429 Enteroid monolayers: Enteroid monolayers were washed 1x with warm D-PBS and then fixed

430 with $4 \%$ paraformaldehyde in PBS for $15 \mathrm{~min}$ at room temperature. Cells were then washed with

431 PBS and permeabilized with 0.5\% Triton-X-100 in PBS at room temperature for 10min. Cells

432 were washed, blocked with 3\% BSA in PBS for 30min, and then incubated in primary antibody

433 in antibody buffer (PBS with $0.3 \%$ Triton-X-100, 1\% BSA) overnight at 4C. The next day, cells 
434 were washed and incubated with secondary antibodies and Hoechst $33342(5 \mu \mathrm{g} / \mathrm{mL}$; Invitrogen

435 \#H3570) in antibody buffer for 2 hours at room temperature. After this, cells were washed with

436 PBS and imaged in TBS-T (0.1\% Tween in 1x TBS pH 7.4).

4373 D organoids: Media was carefully aspirated from around Matrigel domes containing 3D

438 organoids using a P100 pipet. 4\% paraformaldehyde in PBS was immediately added for 15min at

439 room temperature. Cells were then washed 2x with PBS and permeabilized using 0.5\% Triton-X-

440100 in PBS for 20min at room temperature. Cells were then rinsed 3x10min with $100 \mathrm{mM}$

441 glycine in PBS with gentle agitation. Cells were blocked in 3\% BSA in PBS for 40min and then

442 incubated with primary antibody in antibody buffer overnight at room temperature. The next day,

443 cells were washed $3 \times 20 \mathrm{~min}$ in antibody buffer and then incubated with fluorescent secondary

444 antibodies and Hoechst in antibody solution for $1 \mathrm{hr}$ at room temperature. Cells were then rinsed

445 in PBS and stored and imaged in TBS-T.

$447 \quad$ Antibodies

448 All antibodies were purchased from suppliers and used as designated without further

449 purification. Unless otherwise indicated, antibodies were used as follows:

\begin{tabular}{|c|c|c|}
\hline Epitope & Vendor and Catalog \# & Dilution \\
\hline Lysozyme (Lyz) & Dako & $1: 2000$ \\
\hline Mucin-2 (Muc2) & Santa Cruz Biotechnology \#15334 & $1: 100$ \\
\hline Chromogranin A (ChgA) & Santa Cruz Biotechnology \#393941 & $1: 100$ \\
\hline GFP & Abcam \#5450 & $1: 2000$ \\
\hline Dclk1 & Abcam \#31704 & $1: 1000$ \\
\hline $\begin{array}{c}\text { Erk1 (pT202/pY204)+ Erk2 } \\
\text { (pT185/pY187) (pErk) }\end{array}$ & Abcam \#50011 & $1: 200$ \\
\hline Cyclin D1 & Life Technologies \#MA5-14512 & $1: 200$ \\
\hline
\end{tabular}


$451 \quad$ EdU pulse and visualization

452 To visualize proliferating cells (specifically, those in S phase), enteroid monolayers were

453 incubated with $10 \mu \mathrm{M}$ EdU (Thermo Fisher \#A 10044) in media (containing indicated

454 perturbations or vehicle) for $2 \mathrm{hrs}$ prior to fixation. After immunofluorescence staining, EdU

455 cells were visualized using Click chemistry as previously described (Salic \& Mitchison, 2008).

456 Briefly, cells were incubated with a reaction mixture containing $1 \mathrm{mM} \mathrm{CuSO} 4$ (VWR

457 International \#470300-880), $5 \mu \mathrm{M}$ sulfo-Cyanine5 azide (Lumiprobe \#B3330) or $5 \mu \mathrm{M}$ BDP-FL

458 azide (Lumiprobe \#11430), and $100 \mathrm{mM}$ sodium ascorbate (Sigma Aldrich \#A4034) in PBS for

$45930 \mathrm{~min}$ at room temperature.

460

$461 \quad$ Automated brightfield microscopy

462 Upon initial plating, enteroid monolayers were imaged in the brightfield channel using the 10x

463 objective of a Nikon TE200-E epifluorescence microscope. These data were used as a control to

464 determine whether enteroid monolayers were seeded at an optimal and consistent confluency.

465

466 Quantifying \% confluency

$467 \%$ Confluency (percent of image which is occupied by enteroid monolayer cultures) was

468 quantified from brightfield images using a previously reported algorithm

469 (CellularRegionsFromBrightField function in Supplementary Software 1 from reference

470 (Ramirez et al., 2016)).

471

472 Automated confocal microscopy

473 Enteroid monolayers were imaged on the 10x objective of a Nikon A1 confocal with Ti2-E

474 microscope. The area of each well was covered by 24 individual scans. In each field of view, 4-8

$475 \mathrm{z}$ planes were collected at 1024x1024 resolution. Importantly, the nuclear stain was used to

476 autofocus in each new field of view.

477

478 Data availability

479 All data generated or analyzed during this study are included in this published article (and its

480 supplementary information files) 
$\underline{\text { Immunofluorescence image segmentation and analysis }}$

483 General information: Image segmentation was performed using a custom Python analysis

484 pipeline. All code and documentation can be found on GitHub

485 (https://github.com/AltschulerWu-Lab/MAGS). Starting with maximum intensity projections of

486 Hoechst, EdU, Lgr5-GFP, Muc2, Lyz, and ChgA fluorescent images, we segmented and then

487 quantified numbers of nuclei, EdU ${ }^{+}$cells, stem cells, goblet cells, Paneth cells, and

488 enteroendocrine cells, respectively. The general segmentation process for each object type

489 consisted of two major steps: a thresholding step to identify image foreground, and a segmentation step to generate location and boundary of objects. Specific details are as follows:

Segmenting nuclei: Hoechst stain images were smoothed through convolution with a bilateral cultures are highly heterogeneous with small, tightly packed nuclei in the crypt regions and large, sparsely distributed nuclei in the villus regions. Therefore, to obtain an accurate segmentation in these different regions, we conducted a two-step segmentation approach. First, sparse nuclei were identified using a multi-scale Laplacian of Gaussian (LoG) detector to generate markers of object locations. A watershed algorithm was then used to generate object boundaries. Clumps were detected in the sparse segmentation using object size and shape irregularity cutoffs. These clumps contained mis-segmented dense nuclei and were subsequently segmented using differently parameterized LoG detector to identify object seeds and watershed to generate object boundaries. The dense and sparse segmentations were then merged for the final result (also see Figure 1-Supplement 1C).

Segmenting EdU $U^{+}$nuclei: The same process as nuclear segmentation was used because nuclear

506 objects in EdU stain images had similar properties as those in Hoechst stain images.

507 Segmenting stem cells (Figure 1-Supplement 1D): GFP immunofluorescence in enteroid 508 monolayers derived from Lgr5-eGFP-DTR mice (H. Tian et al., 2011) revealed both crypt 509 regions, with multi-cell membrane GFP staining, and single $\mathrm{GFP}^{+}$cells outside crypt regions.

510 The single $\mathrm{GFP}^{+}$cells appeared morphologically similar to tuft cells and co-stained for Dclk-1

511 (Figure 1-Supplement 1E), indicating that these cells are likely a subpopulation of tuft cells 512 rather than stem cells. Therefore, we only identified stem cells within crypt regions. Crypt 
513 regions were defined as clusters of $\mathrm{Lgr}^{+}$stem and Paneth cells, corresponding to crypt bases in

514 vivo. Lgr5-GFP stain images were processed to remove tissue background and thresholded to

515 identify foreground. Holes and gaps in crypt regions were filled using morphological operations

516 and small objects (typically, $\operatorname{Lgr} 5^{+} / \mathrm{Dclk} 1^{+}$cells, see Figure 1-Supplement 1E) were dropped. The

517 remaining objects were labeled as crypts. We then counted nuclei within crypt regions as stem

518 cells. Importantly, we removed any nucleus in a crypt region that was associated with a Paneth

519 cell from the stem cell count (Figure 1-Supplement 1A).

520

521 Identifying Paneth cells: Lysozyme (Lyz) immunofluorescence images were smoothed through

522 convolution with a bilateral filter then a tophat filter. Foreground was identified using the Otsu-

523 thresholded Lyz immunofluorescence image. A LoG detector was then used to generate markers

524 of Paneth object locations.

525

526 Segmenting goblet cells: Mucin-2 (Muc2) stain images were smoothed by convolution with a

527 median filter. Foreground was identified using a convex hull of objects in each Otsu-thresholded

528 Muc2 immunofluorescence image. Goblet cells were segmented using a LoG detector to

529 generate markers of goblet object locations followed by watershed to create object boundaries.

Identifying enteroendocrine (EE) cells: ChgA stain images were processed using the same steps

532 as Paneth cell identification, only with different parameters.

534 Evaluation of Image Segmentation: Each cell-type object (e.g., each nucleus, each goblet cell,

535 each Paneth cell) was identified in raw immunofluorescence images by hand by an expert and, in

536 parallel, using the customized algorithms described above. The expert-generated segmented

537 images (where each mask represents an individual object) were compared to algorithm-generated

538 segmented images to determine algorithm performance. 'Precision' was quantified by dividing

539 the number of true positives (expert-identified objects also identified by the algorithm) by the

540 number of total positives (all algorithm-identified objects). 'Recall' was quantified by dividing

541 the number of true positives by the total number of expert-identified objects. F1 scores were

542 calculated as the harmonic mean of precision and recall. See Table 1 for results. 
544 Data Analysis

545 Extracting numbers of each cell-type: Due to limitations of conventional fluorescence

546 microscopy, all desired cell-types were quantified across two replicate immunofluorescent stain

547 sets: a crypt stain set (Hoechst, EdU, Lgr5-GFP, Lyz) and a differentiated cell stain set (Hoechst,

548 EdU, Muc2, ChgA). We were able to quantify the numbers of some cell-types directly from a

549 single stain set, including the number of each directly measured cell-type $\left(\mathrm{EdU}^{+}\right.$, stem, goblet,

550 Paneth, EE) as well the number of proliferating $\left(\mathrm{EdU}^{+}\right)$stem cells (combining information from

551 EdU and Lgr5-GFP segmentation), transit-amplifying cells (TA; \#EdU ${ }^{+}$cells minus \#stem cells),

552 and differentiated cells (\# cells minus stem and TA cells).

553

554 Replicates and Error Estimation: In-plate replicate control wells (2-6 wells per plate) were used

555 to estimate mean and error. For replicate plates, mean and error were pooled. For across stain-set

556 readouts, error was propagated.

557

558 Fold Change: We calculated fold-change effects relative to in-plate controls for readouts within

559 each stain set (\#EdU ${ }^{+}$stem cell, \#TA cells). Fold-changes for readouts calculated across both

560 stain sets (\#secretory/\#diff, \#goblet/\#secretory, \#Paneth/\#secretory, \#EE/\#secretory) were

561 calculated to a pooled control baseline measurement.

562

$563 \quad$ Statistical testing

564 In comparing enteroid samples, two-sided Welch's t-tests were performed and $p$ values were

565 reported. In comparing in vivo samples, two-sided Student's t tests were performed and p values

566 were reported. Degrees of freedom is taken as n-1. Measurements were taken from distinct

567 samples.

568

569 Perturbation effect visualization

570 For Figure 2B, double perturbation phenotypes were sorted into similar phenotypes using

571 hierarchical clustering (clustermap function in seaborn) with a euclidean distance metric. Single

572 perturbation phenotypes were sorted based on the number of $\mathrm{EdU}^{+}$stem cells in each row. 
575 Population growth model

576 We established a simple population growth model to compute the changes in secretory and

577 absorptive populations in response to cell cycle perturbation. In this model, we assumed that the

578 initial ratio of absorptive to secretory TA progenitors produced by stem cells is equal. We further

579 assumed that the progenitors are locked into either secretory or absorptive fates after the initial

580 commitment with no switching occurring between fates (Stamataki et al., 2011; van Es et al.,

581 2012). The model describes the theoretical output of differentiated cells from populations of

582 initial secretory or absorptive progenitors.

583 Under normal growth (control condition), we describe the amplification of absorptive and

584 secretory TA cells as follows:

585

586

587

588

589

590

591

592

593

594

595

596

597

598

599

600

601

602

603

604

605

$$
\begin{aligned}
A & =A_{0}(2)^{\frac{t}{\tau_{a}}} \\
S & =S_{0}(2)^{\frac{t}{\tau_{s}}}
\end{aligned}
$$

where $A_{0}$ and $S_{0}$ are the numbers of initial absorptive and secretory TA progenitors, respectively. $\mathrm{A}$ and $\mathrm{S}$ are the numbers of final absorptive and secretory differentiated cells, respectively. $\mathrm{t}$ is the total model time, set to be 48 (hours). $\tau_{\mathrm{a}}$ and $\tau_{\mathrm{s}}$ are the cell cycle lengths of absorptive and secretory progenitors, respectively. Absorptive progenitors are generally found to divide 4-5 times while secretory progenitors only divide 1-2 times (Potten, 1998; Stamataki et al., 2011; van Es et al., 2012). We set $\tau_{\mathrm{a}}$ and $\tau_{\mathrm{s}}$ to be 12 and 48 (hours) in control conditions. Thus, secretory progenitors divide once while absorptive progenitors divide four times before fully differentiating, consistent with previous observations. Progenitors that divide fewer times are not considered differentiated cells.

We model the perturbation effect with the parameter $p$, where $p$ is the probability of cell cycle progression for any TA cell (alternatively $1-\mathrm{p}$ is the probability of quiescence). The expected numbers of differentiated absorptive and secretory cells, as averaged over an ensemble of initial progenitor populations, are as follows:

$$
\begin{aligned}
& E(A)=A_{0}(2 p)^{\frac{t}{\tau_{a}}} \\
& E(S)=S_{0}(2 p)^{\frac{t}{\tau_{s}}}
\end{aligned}
$$

where $0<\mathrm{p}<1$ in the case of cell cycle inhibitors and $\mathrm{p}=1$ in the untreated case.

Scanning through different values of $\tau_{\mathrm{a}}$ and $\tau_{\mathrm{s}}$, we observe that as long as $\tau_{\mathrm{a}}$ is less than $\tau_{\mathrm{s}}$, decreasing proliferation (increasing $\mathrm{p}$ ) corresponds to an increase in secretory prevalence. The expectation follows from the observation that $p$ modifies the expected number of progeny per 
606

607

608

609

610

611

612

613

614

615

616

617

618

619

620

621

622

623

624

625

626

627

628

629

630

631

632 2009).

633

634

635

636 follows:

generation to be $2 p$. More explicitly, the expectation of progeny number $\left(X_{i}\right)$ for progenitor generation $i$ can be calculated as follows:

$$
E\left(X_{0}\right)=\sum\left(E\left(X_{1 j}\right)\right)=2 p\left(E\left(X_{1}\right)\right) \ldots=(2 p)^{\# \text { divisions }}=(2 p)^{\frac{t}{\tau}}
$$

We note that we can take a different parametrization for the cell-cycle inhibitor effect where the length of cell cycling is varied under perturbation. The equations for this parametrization are as

$$
\begin{aligned}
& A=A_{0}(2)^{\frac{t}{p^{\prime} \tau_{a}}} \\
& S=S_{0}(2)^{\frac{t}{p^{\prime} \tau_{s}}}
\end{aligned}
$$

where we take $p^{\prime}$ to be a number $>1$ in the case of cell cycle inhibitors and $p=1$ in the untreated case and $\mathrm{t}$ is 48 as before. In this approach, we do not lose progenitors to quiescence and all progenitors are considered differentiated at the end of the experiment time t. Since we can convert between $\mathrm{p}^{\prime}$ and $\mathrm{p}$ by letting $p=2^{\frac{1}{p^{\prime}}-1}$, we would observe a similar outcome as the first parametrization approach where increasing perturbation effect via increased cell cycle inhibition corresponds to an increase in secretory prevalence.

\section{Identifying perturbation interactions}

Multiplicative model: To identify perturbation interactions, we first established a model for how perturbation effects should combine if there is no interaction. A simple model commonly used in genetic and drug interaction studies is the multiplicative model (Mani et al., 2008; van Hasselt \& Iyengar, 2019). Under the multiplicative model, perturbations that do not interact should combine as the product of their respective fold-change effects. This is equivalent to logadditivity, which can be calculated as follows:

$\log _{2} f \mathrm{c}\left(\mathrm{AB}_{\text {predicted }}\right)=\log _{2} \mathrm{fc}\left(\mathrm{A}_{\mathrm{obs}}\right)+\log _{2} \mathrm{fc}\left(\mathrm{B}_{\mathrm{obs}}\right)$

Features with 0 values had a pseudocount of 1 instead. Perturbation combination effects that deviate from the multiplicative model indicate a potential interaction, which we define biologically as the due to utilization of a shared pathway or redundant pathways (Dixon et al., For each perturbation pair, we evaluated how a multiplicative model fits the observed double perturbation effects for each cell-type readout (e.g., \#TA cells). To evaluate the multiplicative model across each perturbation and readout, we plotted the effects of perturbation combinations (e.g, the effects of Wnt3a in combination with all other perturbations on \#TA cells) against the 
637 single perturbations (e.g., all perturbations except Wnt3a) in log scale. The multiplicative model

638

639

640

641

642

643

644

645

646

647

648

649

650

651

652

653

654

655

656

657

658

659

660

661

662

663

664

665

666

prediction is a line offset on the $y$-axis by the effect of the perturbation of interest (Figure 3-

Supplement 1B). Combinations of perturbations that do not exhibit an interaction will have an effect that lies on this line. We compared linear and multiplicative functions for each single perturbation and observed that some single perturbations fit well with either multiplicative or linear fit models, while others deviated significantly from both (e.g., Wnt3a fits well with either model while EGFR-i deviates significantly from both, see Figure 3-Supplement 1B-C). We computed the residuals for perturbation combination fit across all readouts. The two models had similar distributions of residual values with peaks close to zero (Figure 3-Supplement 1A), indicating that the majority of perturbations in our experiment combined in a manner that is well described by the multiplicative model.

Effect size: The deviation of each combinatorial perturbation from the prediction of the multiplicative model is represented as effect size, which was quantified in this case as absolute Cohen's d, or the standardized deviation of the combinatorial phenotype from multiplicative model prediction.

Effect size $=\left|\mu_{\text {obs }}-\mu_{\text {pred }}\right| / \sigma_{\text {pooled }}$

where $\mu_{\mathrm{obs}}$ and $\mu_{\text {pred }}$ are the observed and predicted means for the combination effect and $\sigma_{\text {pooled }}$ is the pooled standard deviation. In Figure 3A, the cut-off for the effect size was 5.

\section{BMP2 ELISA}

Supernatant levels of BMP2 were quantified using a BMP-2 Quantikine ELISA kit (R\&D Systems \#DBP200), without significant deviations from manufacturer's instructions.

\section{qRT-PCR}

RNA was harvested from enteroid monolayers using an RNEasy Plus Mini Kit (Qiagen \#74136). Reverse transcription was performed using iScript Reverse Transcription kit (Bio-Rad \#1708841). Quantitative PCR was performed using SsoAdvanced Universal SYBR Green Supermix (Bio-Rad \#1725272) on a BioRad CFXConnect. Test gene values were normalized to beta-actin values. To quantify Atoh1/Hes1 ratio, both Atoh1 and Hes1 fold-changes relative to 
667 control were calculated and then Atoh1 fold-change was divided by Hes 1 fold-change. RNA

668 levels were determined using the following primers:

\begin{tabular}{|l|l|l|}
\hline $\begin{array}{l}\text { Target } \\
\text { mRNA }\end{array}$ & Forward Primer & Reverse Primer \\
\hline Atoh1 & 5'-TCCCCTTCCTCCTACCTTCTCC-3' & 5'-CAACACGCAAGGATGAACTCCC-3' \\
\hline Hes1 & 5'-AGAAGAGGCGAAGGGCAAGAAT-3' & 5'-TGGAATGCCGGGAGCTATCTTT-3' \\
\hline Lyz & 5'-AAGAATGCCTGTGGGATCAA-3' & 5'-CGGTTTTGACATTGTGTTCG-3' \\
\hline Muc2 & 5'-ACCCCAAGCCCTTCTCCTACTA-3' & 5'-AGTGGATTGAGAGGTCACAGGC-3' \\
\hline ChgA & 5'-GCAACACAGCAGCTTTGAGGAT-3' & 5'-GTTAGGCTCTGGAAAGGCCTGA-3' \\
\hline Bmp2 & 5'-GCTTCTTAGACGGACTGCGG-3' & 5'-GCAACACTAGAAGACAGCGGGT-3' \\
\hline beta-actin & 5'-CGCCACCAGTTCGCCATGGA-3' & 5'-TACAGCCCGGGGAGCATCGT-3' \\
\hline
\end{tabular}

\section{Acknowledgments}

671 We are grateful to Zev Gartner, Ophir Klein, Curtis Thorne, and members of the Altschuler-Wu

672 lab for their feedback. We additionally thank Ophir Klein and Frederic de Sauvage for mouse

673 resources. This work was supported by NIH GM112690 (S.J.A.), NCI-NIH RO1 CA184984

674 (L.F.W.), the UCSF Program for Breakthrough Biomedical Research which is partly funded by

675 the Sandler Foundation (L.F.W.), NIH NRSA fellowship F32DK120102 (L.E.S.), and NSF

676 GRFP fellowship 1650113 (I.W.C.).

677 Author contributions

678 I.W.C. and L.E.S. conceptualized study, developed computational methods, designed and

679 executed experiments, analyzed data, and wrote the manuscript. J.M.B. and V.S. designed and 
680 executed in vivo experiments and analyzed data. B.H. supervised the in vivo study. L.F.W. and

681 S.J.A. conceptualized and supervised the overall study and wrote the manuscript.

\section{Competing interests}

683 Authors declare no competing interests. 


\section{References}

685

686

687

688

689

690

691

692

693

694

695

696

697

698

699

700

701

702

703

704

705

706

707

708

Balázsi, G., van Oudenaarden, A., \& Collins, J. J. (2011). Cellular decision making and biological noise: from microbes to mammals. Cell, 144(6), 910-925.

Barnard, J. A., Beauchamp, R. D., Coffey, R. J., \& Moses, H. L. (1989). Regulation of intestinal epithelial cell growth by transforming growth factor type beta. In Proceedings of the National Academy of Sciences (Vol. 86, Issue 5, pp. 1578-1582). https://doi.org/10.1073/pnas.86.5.1578

Basak, O., Beumer, J., Wiebrands, K., Seno, H., van Oudenaarden, A., \& Clevers, H. (2017a). Induced Quiescence of Lgr5+ Stem Cells in Intestinal Organoids Enables Differentiation of HormoneProducing Enteroendocrine Cells. Cell Stem Cell, 20(2), 177-190.e4.

Batlle, E., Henderson, J. T., Beghtel, H., van den Born, M. M. W., Sancho, E., Huls, G., Meeldijk, J., Robertson, J., van de Wetering, M., Pawson, T., \& Clevers, H. (2002). Beta-catenin and TCF mediate cell positioning in the intestinal epithelium by controlling the expression of EphB/ephrinB. Cell, 111(2), 251-263.

Beumer, J., \& Clevers, H. (2016). Regulation and plasticity of intestinal stem cells during homeostasis and regeneration. Development, 143(20), 3639-3649.

Birchenough, G. M. H., Nyström, E. E. L., Johansson, M. E. V., \& Hansson, G. C. (2016). A sentinel goblet cell guards the colonic crypt by triggering Nlrp6-dependent Muc2 secretion. Science, $352(6293), 1535-1542$.

Bjerknes, M., \& Cheng, H. (1999). Clonal analysis of mouse intestinal epithelial progenitors. Gastroenterology, 116(1), 7-14.

Cheng, H., \& Leblond, C. P. (1974a). Origin, differentiation and renewal of the four main epithelial cell types in the mouse small intestine. I. Columnar cell. The American Journal of Anatomy, 141(4), $461-479$.

Cheng, H., \& Leblond, C. P. (1974b). Origin, differentiation and renewal of the four main epithelial cell types in the mouse small intestine. V. Unitarian Theory of the origin of the four epithelial cell types. 
The American Journal of Anatomy, 141(4), 537-561.

710 Clevers, H. (2013). The intestinal crypt, a prototype stem cell compartment. Cell, 154(2), 274-284.

711 Coster, A. D., Thorne, C. A., Wu, L. F., \& Altschuler, S. J. (2017). Examining Crosstalk among

712 Transforming Growth Factor $\beta$, Bone Morphogenetic Protein, and Wnt Pathways. The Journal of

713 Biological Chemistry, 292(1), 244-250.

714 Dames, P., Bergann, T., Fromm, A., Bücker, R., Barmeyer, C., Krug, S. M., Fromm, M., \& Schulzke, J.-

715 D. (2015). Interleukin-13 affects the epithelial sodium channel in the intestine by coordinated

716 modulation of STAT6 and p38 MAPK activity. The Journal of Physiology, 593(24), 5269-5282.

717 Dixon, S. J., Costanzo, M., Baryshnikova, A., Andrews, B., \& Boone, C. (2009). Systematic mapping of genetic interaction networks. Annual Review of Genetics, 43, 601-625.

Farin, H. F., Jordens, I., Mosa, M. H., Basak, O., Korving, J., Tauriello, D. V. F., de Punder, K., Angers,

Flentjar, N., Chu, P.-Y., Ng, A. Y.-N., Johnstone, C. N., Heath, J. K., Ernst, M., Hertzog, P. J., \&

Flier, L. G. van der, van der Flier, L. G., \& Clevers, H. (2009). Stem Cells, Self-Renewal, and Differentiation in the Intestinal Epithelium. In Annual Review of Physiology (Vol. 71, Issue 1, pp. 241-260). https://doi.org/10.1146/annurev.physiol.010908.163145

Goldman, D. C., Donley, N., \& Christian, J. L. (2009). Genetic interaction between Bmp2 and Bmp4 reveals shared functions during multiple aspects of mouse organogenesis. Mechanisms of Development, 126(3-4), 117-127. Howitt, M. R., Katz, Y., Tirosh, I., Beyaz, S., Dionne, D., Zhang, M., Raychowdhury, R., Garrett, W. S., Rozenblatt-Rosen, O., Shi, H. N., Yilmaz, O., ... Regev, A. (2017). A single-cell survey of the small intestinal epithelium. Nature, 551(7680), 333-339. 
735

736

737

738

739

740

741

742

743

744

745

746

747

748

749

750

751

752

753

754

755

756

757

758

759

760

Han, L., Diehl, A., Nguyen, N. K., Korangath, P., Teo, W., Cho, S., Kominsky, S., Huso, D. L., Feigenbaum, L., Rein, A., Argani, P., Landberg, G., Gessler, M., \& Sukumar, S. (2014). The Notch pathway inhibits TGF $\beta$ signaling in breast cancer through HEYL-mediated crosstalk. Cancer Research, 74(22), 6509-6518.

Hong, S. P., Song, S., Cho, S. W., Lee, S., Koh, B. I., Bae, H., Kim, K. H., Park, J.-S., Do, H.-S., Im, I., Heo, H. J., Ko, T. H., Park, J.-H., Youm, J. B., Kim, S.-J., Kim, I., Han, J., Han, Y.-M., \& Koh, G. Y. (2017). Generation of PDGFR $\alpha$ Cardioblasts from Pluripotent Stem Cells. Scientific Reports, 7, 41840.

Houde, M., Laprise, P., Jean, D., Blais, M., Asselin, C., \& Rivard, N. (2001). Intestinal epithelial cell differentiation involves activation of $\mathrm{p} 38$ mitogen-activated protein kinase that regulates the homeobox transcription factor CDX2. The Journal of Biological Chemistry, 276(24), 21885-21894.

Lander, A. D., Gokoffski, K. K., Wan, F. Y. M., Nie, Q., \& Calof, A. L. (2009). Cell lineages and the logic of proliferative control. PLoS Biology, 7(1), e15.

Li, Y., Liu, Y., Liu, B., Wang, J., Wei, S., Qi, Z., Wang, S., Fu, W., \& Chen, Y.-G. (2018). A growth factor-free culture system underscores the coordination between Wnt and BMP signaling in Lgr5 intestinal stem cell maintenance. Cell Discovery, 4, 49.

Mani, R., St Onge, R. P., Hartman, J. L., 4th, Giaever, G., \& Roth, F. P. (2008). Defining genetic interaction. Proceedings of the National Academy of Sciences of the United States of America, 105(9), 3461-3466.

Matsu-Ura, T., Dovzhenok, A., Aihara, E., Rood, J., Le, H., Ren, Y., Rosselot, A. E., Zhang, T., Lee, C., Obrietan, K., Montrose, M. H., Lim, S., Moore, S. R., \& Hong, C. I. (2016). Intercellular Coupling of the Cell Cycle and Circadian Clock in Adult Stem Cell Culture. Molecular Cell, 64(5), 900-912.

Papin, J. A., Hunter, T., Palsson, B. O., \& Subramaniam, S. (2005). Reconstruction of cellular signalling networks and analysis of their properties. Nature Reviews. Molecular Cell Biology, 6(2), 99-111.

Potten, C. S. (1998). Stem cells in gastrointestinal epithelium: numbers, characteristics and death. Philosophical Transactions of the Royal Society of London. Series B, Biological Sciences, 
$353(1370), 821-830$.

Qi, Z., Li, Y., Zhao, B., Xu, C., Liu, Y., Li, H., Zhang, B., Wang, X., Yang, X., Xie, W., Li, B., Han, J.D. J., \& Chen, Y.-G. (2017). BMP restricts stemness of intestinal Lgr5 stem cells by directly suppressing their signature genes. Nature Communications, $8,13824$.

Ramirez, M., Rajaram, S., Steininger, R. J., Osipchuk, D., Roth, M. A., Morinishi, L. S., Evans, L., Ji, W., Hsu, C.-H., Thurley, K., Wei, S., Zhou, A., Koduru, P. R., Posner, B. A., Wu, L. F., \& Altschuler, S. J. (2016). Diverse drug-resistance mechanisms can emerge from drug-tolerant cancer persister cells. Nature Communications, 7, 10690.

770

771

Richmond, C. A., Rickner, H., Shah, M. S., Ediger, T., Deary, L., Zhou, F., Tovaglieri, A., Carlone, D. L., \& Breault, D. T. (2018a). JAK/STAT-1 Signaling Is Required for Reserve Intestinal Stem Cell Activation during Intestinal Regeneration Following Acute Inflammation. Stem Cell Reports, 10(1),

Rodríguez-Colman, M. J., Schewe, M., Meerlo, M., Stigter, E., Gerrits, J., Pras-Raves, M., Sacchetti, A., (2017). Interplay between metabolic identities in the intestinal crypt supports stem cell function. Nature, 543(7645), 424-427.

Salic, A., \& Mitchison, T. J. (2008). A chemical method for fast and sensitive detection of DNA synthesis in vivo. Proceedings of the National Academy of Sciences, 105(7), 2415-2420.

Sato, T., Stange, D. E., Ferrante, M., Vries, R. G. J., Van Es, J. H., Van den Brink, S., Van Houdt, W. J.,

Sato, T., Vries, R. G., Snippert, H. J., van de Wetering, M., Barker, N., Stange, D. E., van Es, J. H., Abo, Pronk, A., Van Gorp, J., Siersema, P. D., \& Clevers, H. (2011). Long-term expansion of epithelial organoids from human colon, adenoma, adenocarcinoma, and Barrett's epithelium. Gastroenterology, 141(5), 1762-1772. A., Kujala, P., Peters, P. J., \& Clevers, H. (2009). Single Lgr5 stem cells build crypt-villus structures in vitro without a mesenchymal niche. Nature, 459(7244), 262-265.

Stamataki, D., Holder, M., Hodgetts, C., Jeffery, R., Nye, E., Spencer-Dene, B., Winton, D. J., \& Lewis, 
J. (2011). Delta1 expression, cell cycle exit, and commitment to a specific secretory fate coincide within a few hours in the mouse intestinal stem cell system. PloS One, 6(9), e24484.

Thorne, C. A., Chen, I. W., Sanman, L. E., Cobb, M. H., Wu, L. F., \& Altschuler, S. J. (2018). Enteroid Monolayers Reveal an Autonomous WNT and BMP Circuit Controlling Intestinal Epithelial Growth and Organization. Developmental Cell, 44(5), 624-633.e4.

Tian, A., Benchabane, H., Wang, Z., \& Ahmed, Y. (2016). Regulation of Stem Cell Proliferation and Cell Fate Specification by Wingless/Wnt Signaling Gradients Enriched at Adult Intestinal Compartment Boundaries. PLoS Genetics, 12(2), e1005822.

Tian, H., Biehs, B., Warming, S., Leong, K. G., Rangell, L., Klein, O. D., \& de Sauvage, F. J. (2011). A reserve stem cell population in small intestine renders Lgr5-positive cells dispensable. Nature,

van der Flier, L. G., \& Clevers, H. (2009). Stem cells, self-renewal, and differentiation in the intestinal epithelium. Annual Review of Physiology, 71, 241-260.

van der Flier, L. G., Haegebarth, A., Stange, D. E., van de Wetering, M., \& Clevers, H. (2009). OLFM4 is a robust marker for stem cells in human intestine and marks a subset of colorectal cancer cells.

VanDussen, K. L., Carulli, A. J., Keeley, T. M., Patel, S. R., Puthoff, B. J., Magness, S. T., Tran, I. T., Maillard, I., Siebel, C., Kolterud, Å., Grosse, A. S., Gumucio, D. L., Ernst, S. A., Tsai, Y.-H., Dempsey, P. J., \& Samuelson, L. C. (2012). Notch signaling modulates proliferation and 
Cell Biology, 14(10), 1099-1104.

814 van Hasselt, J. G. C., \& Iyengar, R. (2019). Systems Pharmacology: Defining the Interactions of Drug

815 Combinations. Annual Review of Pharmacology and Toxicology, 59, 21-40.

816 von Moltke, J., Ji, M., Liang, H.-E., \& Locksley, R. M. (2015). Tuft-cell-derived IL-25 regulates an

817 intestinal ILC2-epithelial response circuit. Nature, 529(7585), 221-225.

818 Yin, X., Farin, H. F., van Es, J. H., Clevers, H., Langer, R., \& Karp, J. M. (2014a). Niche-independent

819 high-purity cultures of Lgr5+ intestinal stem cells and their progeny. Nature Methods, 11(1), 106112. 


\section{$821 \quad$ Figures}

A

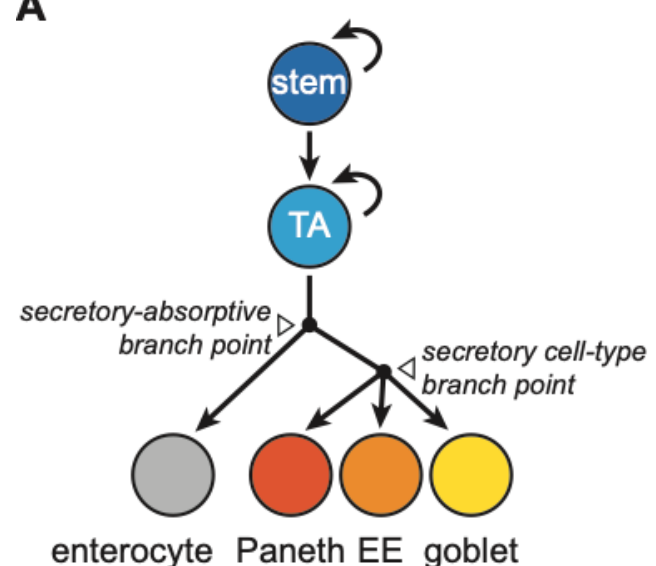

$\frac{\text { enterocyte }}{\text { absorptive }} \frac{\text { Paneth EE goblet }}{\text { secretory }}$

C

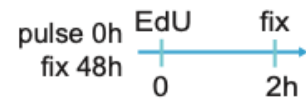
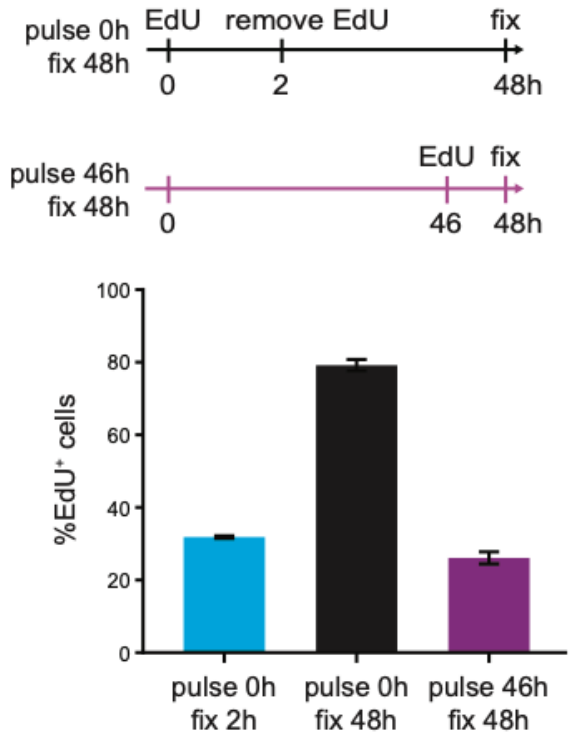

B

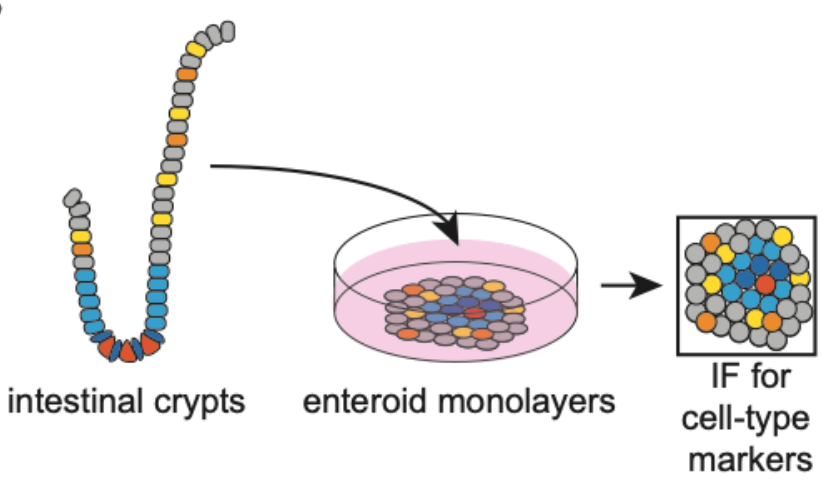

D
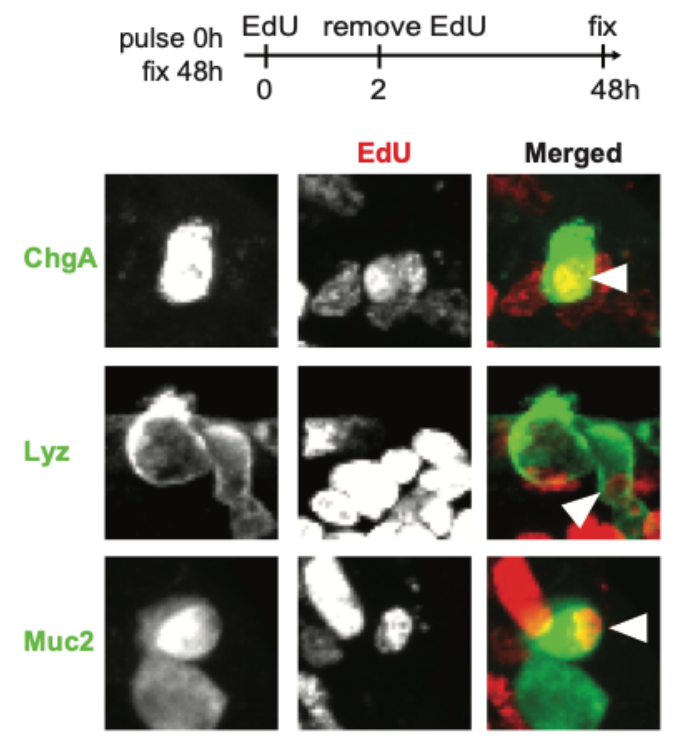

824 composition. (A) Intestinal epithelial cell lineage diagram. (B) Workflow for characterization of

825 perturbation effects on cell-type composition. Intestinal crypts are cultured as enteroid

826 monolayers. Cell-type numbers are measured from immunofluorescence (IF) images of enteroid

827 monolayers. (C) $\sim 80 \%$ of cells in 48 hours of enteroid culture are produced by initial 
828 progenitors. Enteroid monolayers were seeded and either EdU was added for 2 hours and

829 enteroids were then fixed (cyan), EdU was pulsed for 2 hours and removed for 46 hours before

830 fixation (black), or enteroids were cultured for 46 hours and EdU added for the 2 hours prior to

831 fixation (magenta). $\sim 20-30 \%$ of cells are proliferating $\left(\mathrm{EdU}^{+}\right)$upon initial seeding (cyan) and

832 after 48 hours of culture (magenta), and $\sim 80 \%$ of cells are produced by initially proliferating

833 progenitors $\left(\mathrm{EdU}^{+}\right)$in the 48 -hour culture period (black). $\mathrm{n}=3$ wells. (D) Initial progenitors

834 produce secretory cell-types during 48 hours of culture. Enteroids were pulsed with EdU for 2

835 hours upon initial seeding. EdU was removed and cells were fixed after 46 hours of culture. EdU

836 and cell-type marker (Lyz; Paneth, Muc2; goblet, and ChgA; EE) staining patterns were then

837 visualized. Arrowheads indicate cells that co-stain for EdU and the indicated cell-type markers.

838 Error bars mean $+/-$ sem. 
A

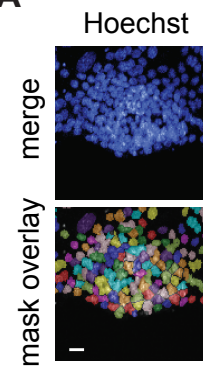

nuclei

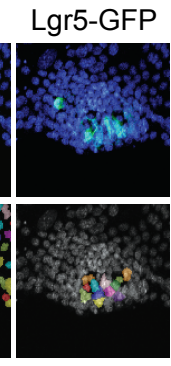

stem cells

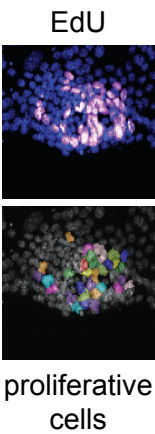

cells
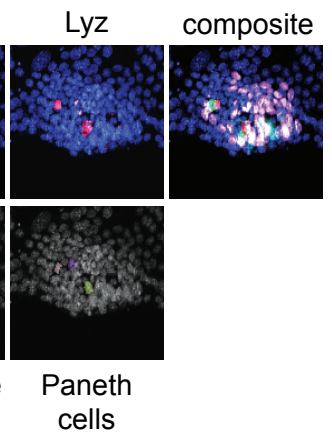

$\mathbf{B}$

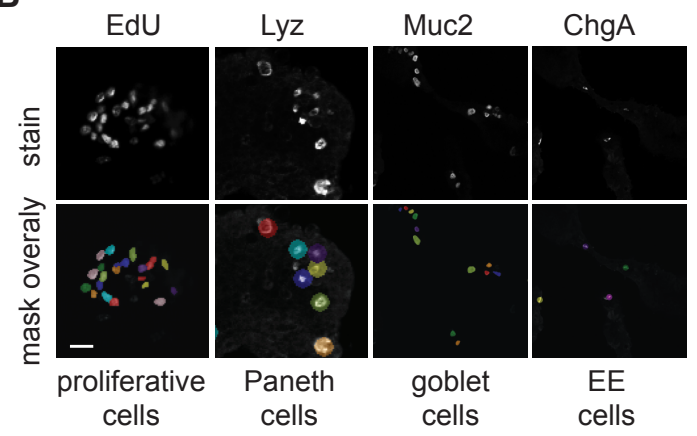

C
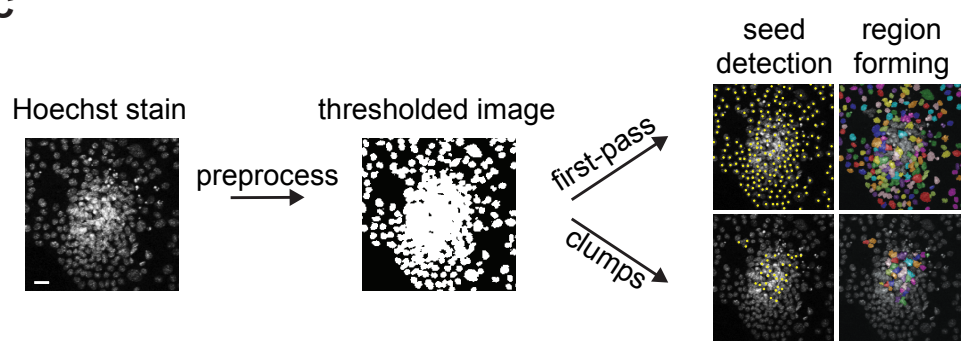

D

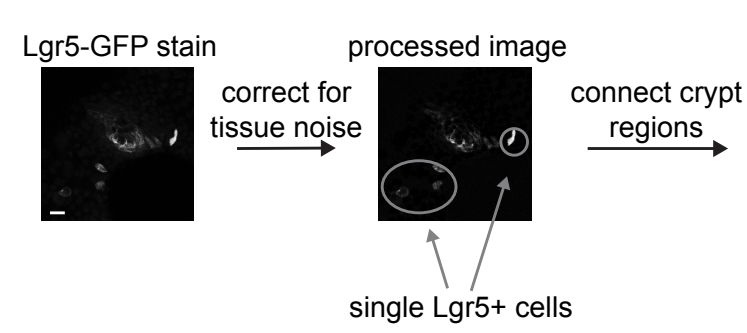

E
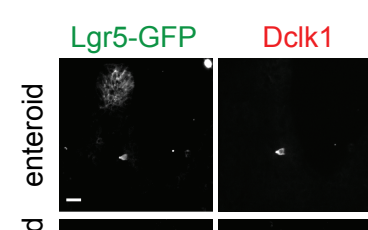

merge

with Hoechst
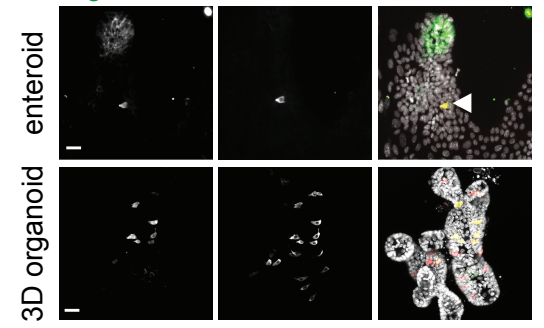

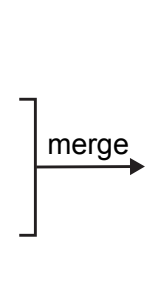

nuclear segmentation

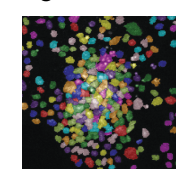

crypt

segmentation

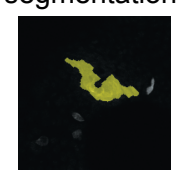

stem cell segmentation

Paneth and partial nuclei

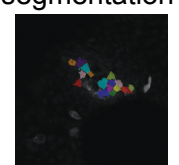

\section{Figure 1-Supplement 1. Quantification of intestinal epithelial cell-types in}

841 immunofluorescence images of enteroid monolayers. (A) Example of crypt segmentation with

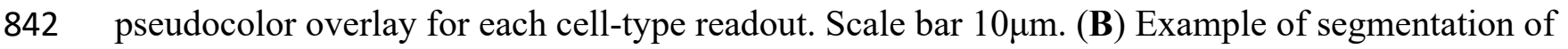

843 proliferating, Paneth, goblet, and enteroendocrine (EE) cells. Top is raw immunofluorescence 
844 image for indicated marker and bottom includes pseudocolor overlay of each identified cell

845 object. Scale bar $10 \mu \mathrm{m}$. (C) Schematic of nuclear segmentation steps. Thresholded Hoechst stain

846 images were segmented in two passes. The first pass segmented sparse nuclei and the second

847 pass segmented clumped nuclei. Sparse and clumped segmentation were merged into the final

848 nuclear segmentation. Yellow dots indicate identified markers of nuclear object locations, multi-

849 pseudocolor overlay depicts individual nuclei segmented using a watershed algorithm. Scale bar

$85010 \mu \mathrm{m}$. (D) Schematic of stem cell segmentation. The Lgr5-GFP stain was first corrected for

851 tissue noise and then thresholded. Size filtering was used to separate multi-cell membrane GFP

852 regions (crypt regions) from single Lgr5-GFP+ cells. All nuclei in crypt regions (nuclei

853 identified from Hoechst image segmentation of same region), with the exception of Paneth cell-

854 associated nuclei, were counted as stem cells. Scale bar 10 $\mu$. (E) Single Lgr5-GFP+ cells are

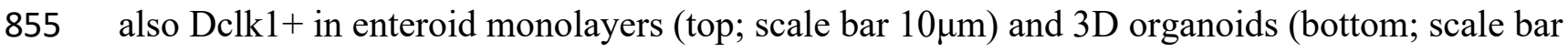

$85615 \mu \mathrm{m})$ and are thus excluded from stem cell counts. 

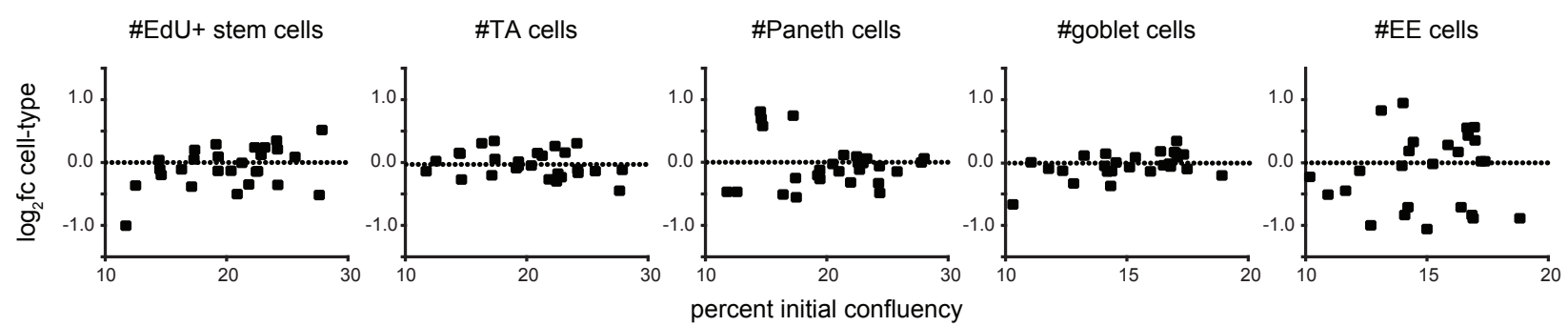

858 Figure 1-Supplement 2. Enteroid monolayers exhibit reproducible cell-type composition

859 across replicate wells when crypts are seeded at $\mathbf{1 0 - 3 0 \%}$ initial confluency. Percent initial

860 confluency was measured from brightfield images taken after crypt seeding and 48hr cell-type

861 composition was quantified from immunofluorescence images. Y axis $\log _{2} f \mathrm{f}$ was computed

862 relative to the average of all wells. No relationship is observed between initial confluency and

863 cell frequencies. 
bioRxiv preprint doi: https://doi.org/10.1101/840371; this version posted March 12, 2020. The copyright holder for this preprint (which was not

A

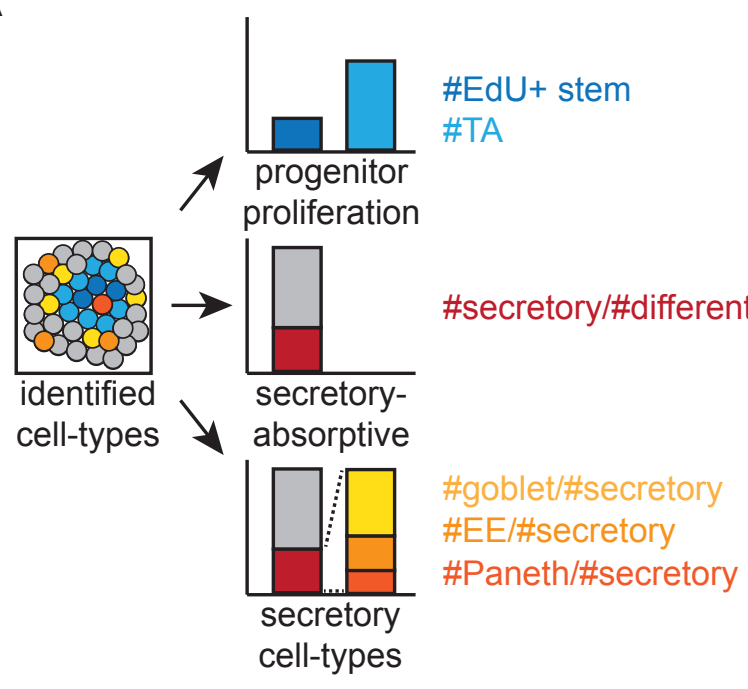

B

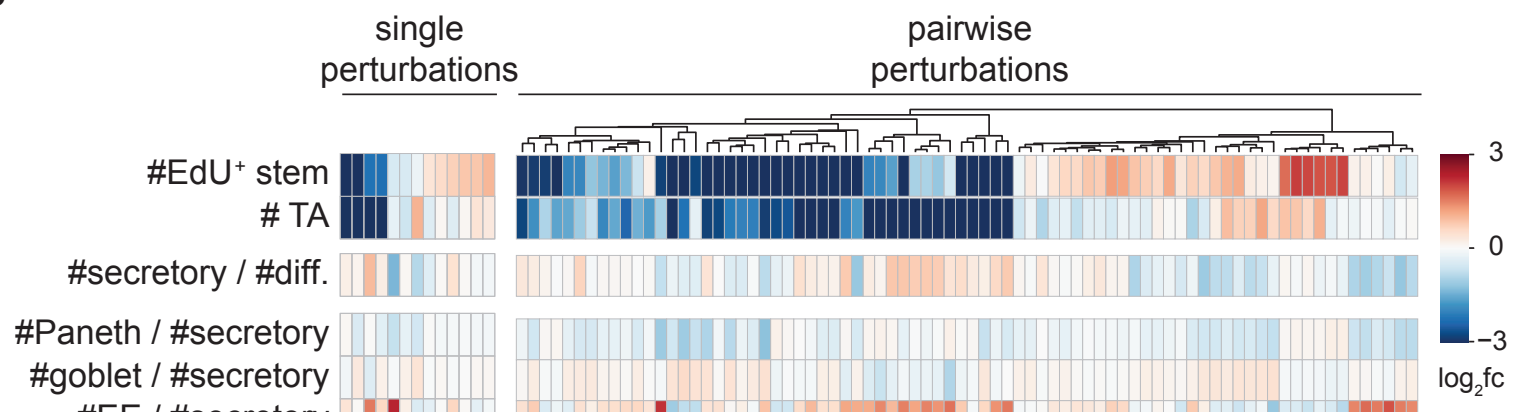

C

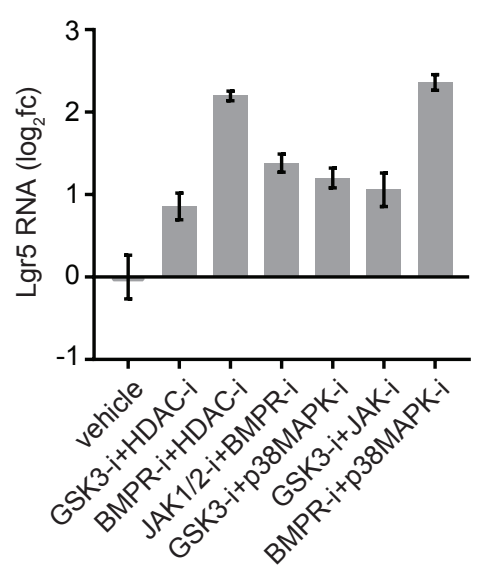

D

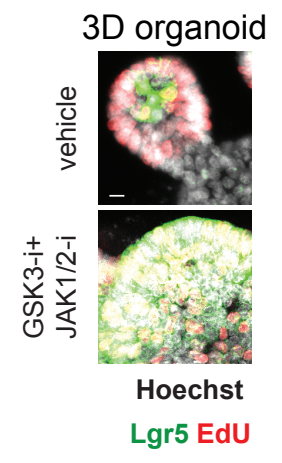

$\mathbf{E}$

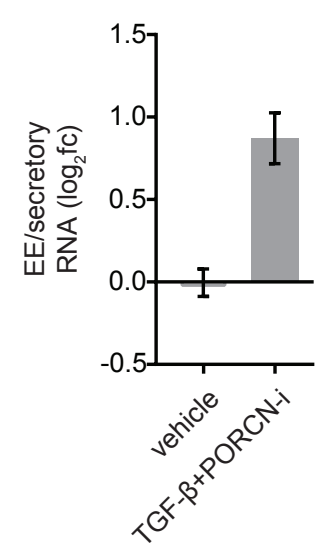

F

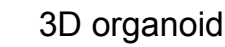


Figure 2. Systematic characterization of perturbation effects on intestinal epithelial celltype composition reveals cell-type-specific regulators. (A), Cell-type counts are combined to

867 quantify progenitor proliferation (top), overall secretory cell prevalence (middle), and

868 representation of each secretory cell-type within that lineage (bottom). (B) Combinatorial

869 perturbations induce diverse phenotypes. Single (left) and pairwise (right) perturbation effects

870 are shown. Top colored heatmaps: Perturbation effects are represented as $\log _{2}$ fold-change (fc)

871 relative to vehicle-treated wells. Bottom black-and-white heatmap: Black boxes indicate

872 perturbations in each column. Single perturbations are sorted by \#EdU ${ }^{+}$stem cells; combinatorial

873 perturbations are clustered based on similarity of tissue-wide effects. Callouts (1) and (2)

874 referred to in text. $\mathrm{n}=2-28$ wells. (C-D) Recapitulation of Lgr $^{+}$stem cell-inducing conditions by

875 qRT-PCR in enteroid monolayers and IF in 3D organoids. (C) Enteroid monolayers were treated

876 as indicated for 48 hours. RNA levels were measured by qRT-PCR. n=3 wells. (D) Lgr5-GFP-

877 DTR 3D organoids were treated as indicated for 48 hours. EdU was added for 2 hours prior to

878 fixation. (E-F) Recapitulation of EE cell inducing condition by qRT-PCR in enteroid monolayers

879 and IF in 3D organoids. (E) Enteroid monolayers were treated as indicated for 48 hours. Changes

880 in EE cell RNA (ChgA) relative to average of secretory cell RNA (ChgA+Lyz+Muc2) was

881 measured by qRT-PCR. n=3 wells. (F) 3D organoids were treated as indicated for 24 hours and

882 increased EE $\left(\mathrm{ChgA}^{+}\right)$cell numbers were observed. Error bars mean +/- sem. 
A

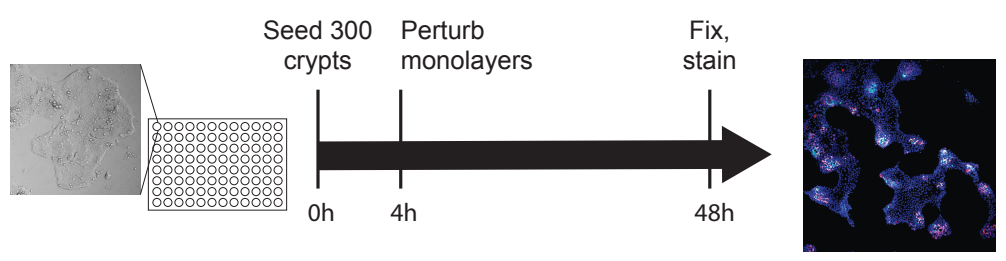

B
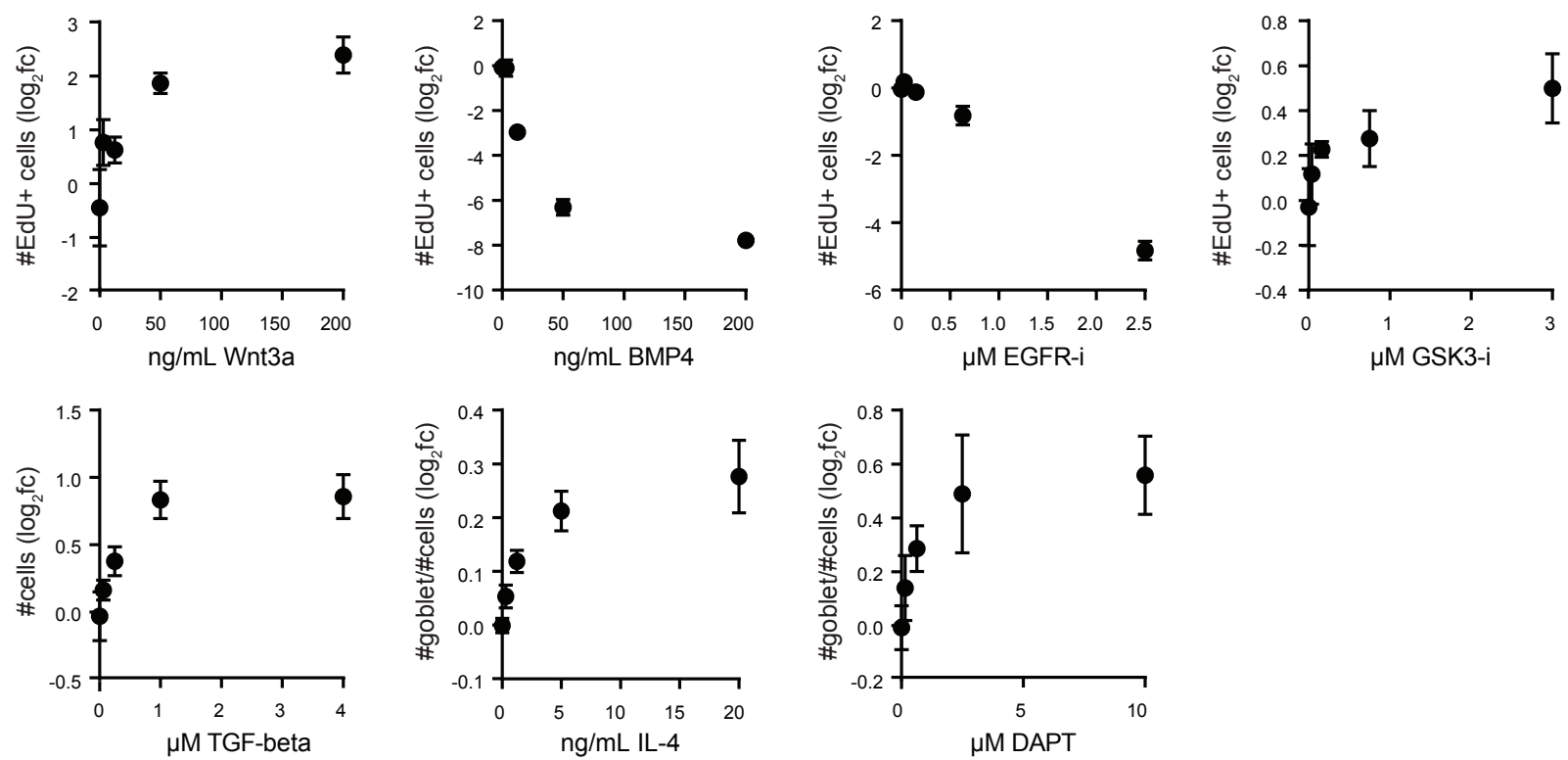

Figure 2-Supplement 1. Optimization of perturbation dose. (A) Schematic of experimental

885 procedure for investigating tissue responses to perturbation. (B) Quantification of cell numbers

886 and prevalence after perturbation with increasing doses of Wnt3a, BMP4, EGFR inhibitor, GSK3

887 inhibitor, TGF-beta, IL-4, or Notch inhibitor. All data are represented as $\log _{2}$ transform of the

888 fold-change effect relative to control. Fraction of goblet cells was calculated as a percentage of

889 all cells for comparison with previous studies. $n=2-6$ wells. Error bars mean +/- sem. 
A

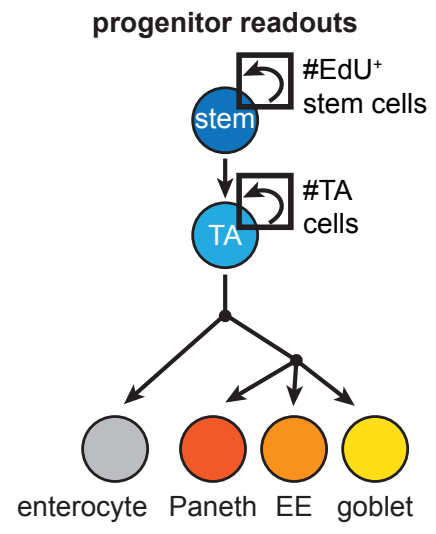

B

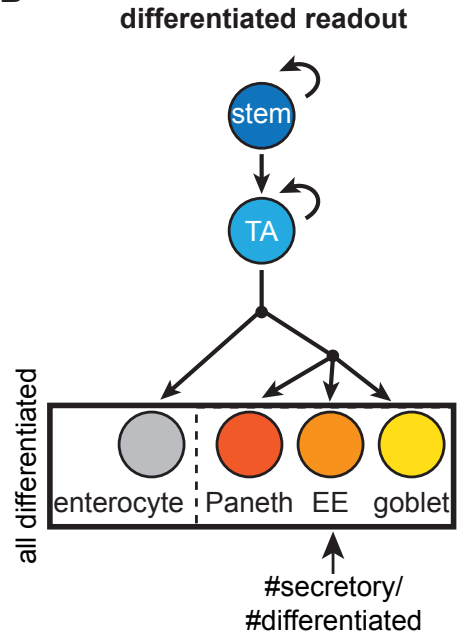

C

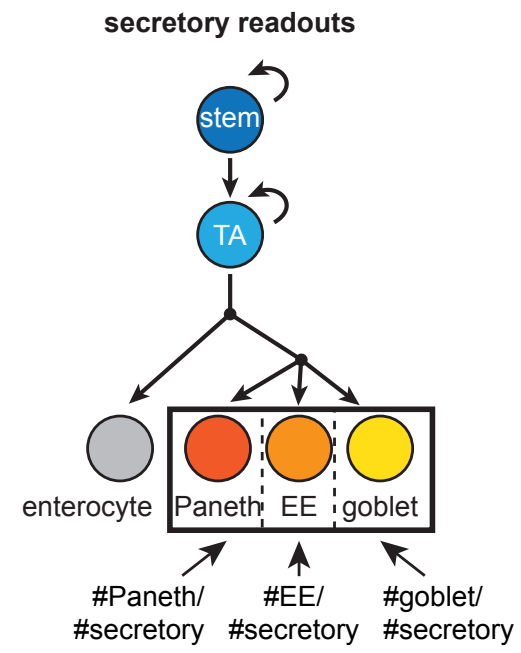

891 Figure 2-Supplement 2. Combining cell-type numbers into readouts of progenitor

892 proliferation and differentiated cell composition. (A) Numbers of proliferating progenitors

893 were quantified as the \#EdU ${ }^{+}$cells, which was further divided into proliferating stem and transit-

894 amplifying (TA) cells based on Lgr5 staining. (B) The secretory-absorptive bias was quantified

895 as the fraction of differentiated cells (EdU- and $\left.\mathrm{Lgr}^{-}\right)$that express secretory markers (the total

896 number of cells that express Paneth (Lyz), goblet (Muc2), or enteroendocrine (EE) cell (ChgA)

897 markers). (C) Composition of the secretory lineage was quantified as the fraction of secretory

898 cells that express either goblet, Paneth, or EE cell markers. 

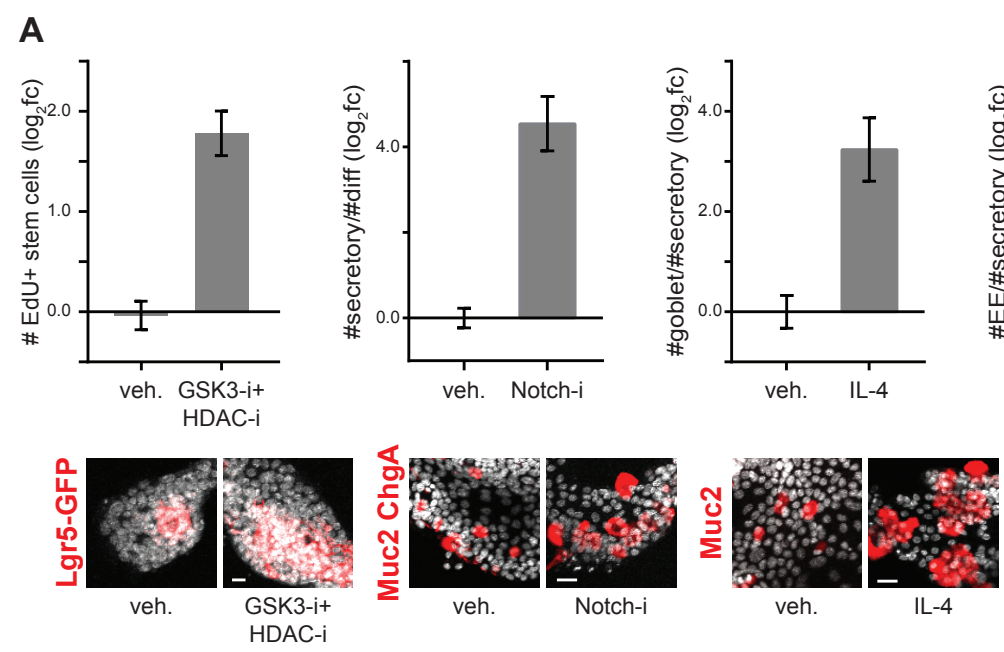

veh.
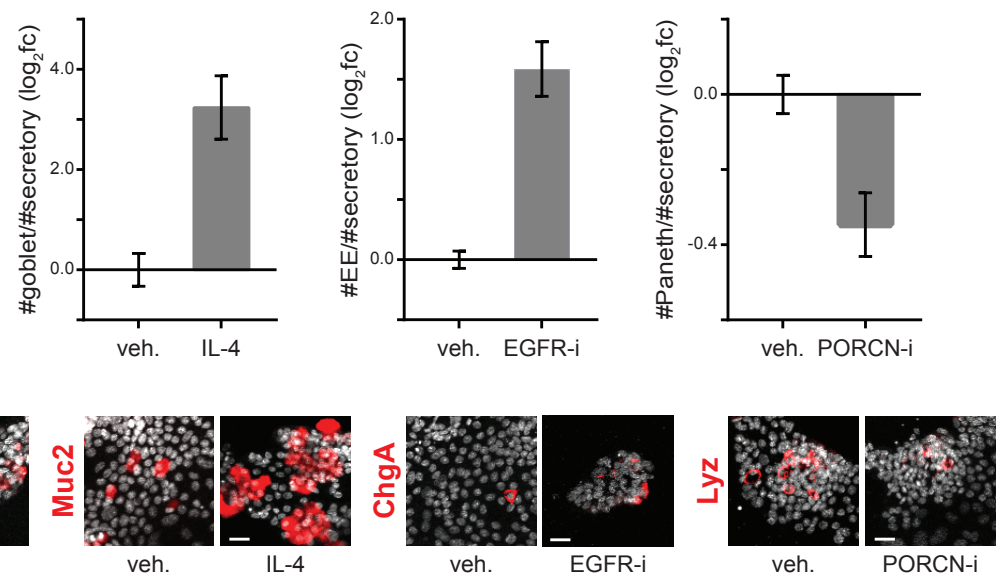

B
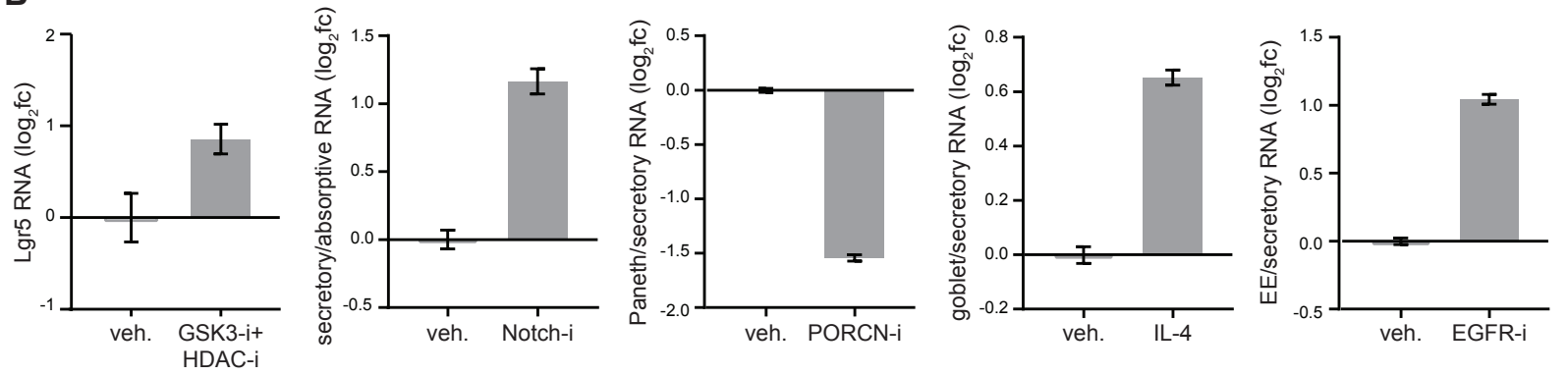

Figure 2-Supplement 3. Benchmarking enteroid monolayer responses to well-characterized

perturbations. (A) Enteroid monolayers respond as expected to modulators of stemness (GSK3-

902 i+HDAC-i) and secretory cell prevalence (Notch-i, IL-4, EGFR-i, PORCN-i). Both

903 quantification of replicate wells (top, $n=2-6$ wells) and representative images (bottom) are

904 shown. Scale bars $10 \mu \mathrm{m}$. (B) Similar changes in cell-type composition are observed at the RNA

905 level. Enteroid monolayers were treated as indicated for 48 hours. For secretory:absorptive RNA,

906 the Atoh1/Hes1 ratio was measured. Paneth RNA=Lyz, goblet RNA=Muc2, EE RNA=ChgA,

907 secretory RNA=Lyz+Muc2+ChgA. n=3 wells. Error bars mean +/- sem. Veh=vehicle. 
A

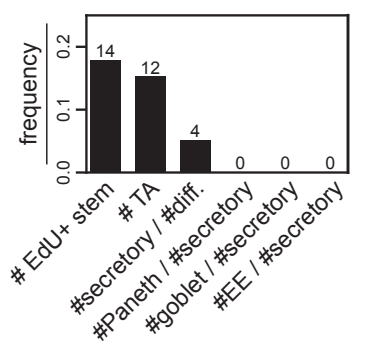

D

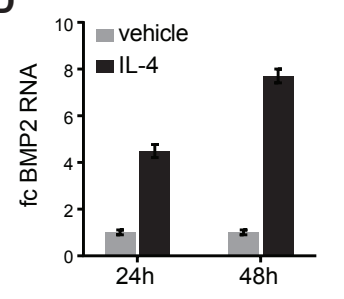

B

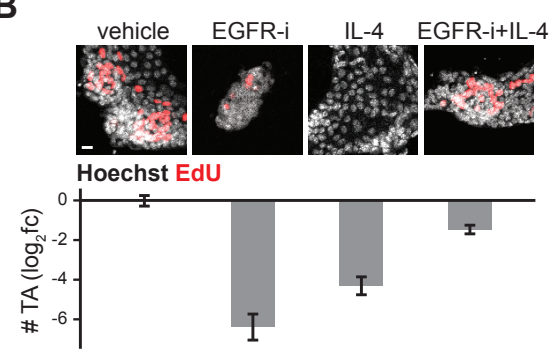

E

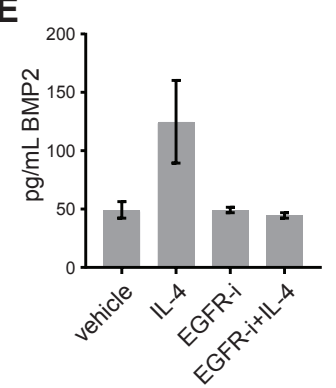

C

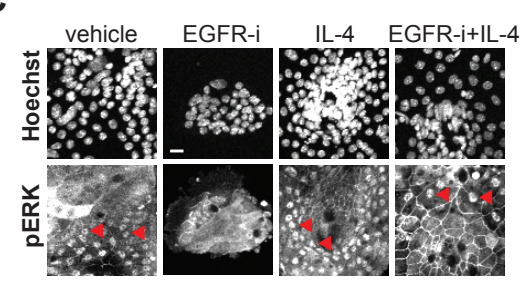

Figure 3. Interaction mapping reveals mutual antagonism between EGFR-i and IL-4. (A)

910 Perturbation interactions are predominantly observed in the regulation of $\mathrm{EdU}^{+}$stem and TA cell

911 numbers. The frequency of perturbation pairs that exhibit significant deviation from the

912 multiplicative expectation was quantified for each readout of cell-type composition. (B) EGFR-i

913 and IL-4 antagonize each other's effects on TA numbers. Enteroid monolayers were treated as

914 indicated for 48 hours. Images (top) and quantification of TA cell numbers (bottom) are shown.

915 n=2-6 wells. (C) IL-4 induces phospho-Erk nuclear translocation in the context of EGFR

916 inhibition. Enteroid monolayers were treated as indicated for 48 hours and then stained for

917 phospho-Erk. Nuclear phospho-Erk is observed in all conditions except EGFR-i alone. Red

918 arrowheads indicate example cells with nuclear phospho-Erk. (D) IL-4 induces BMP2

919 production. Enteroid monolayers were treated as indicated and BMP2 RNA levels measured by

920 qRT-PCR. n=3 wells. (E) EGFR-i abrogates the IL-4-induced increase in BMP2 production.

921 Enteroid monolayers were treated as indicated for 48 hours and levels of BMP2 in the media

922 measured by ELISA. n=3 wells. Error bars mean $+/-$ sem. Fc=fold-change. 
A

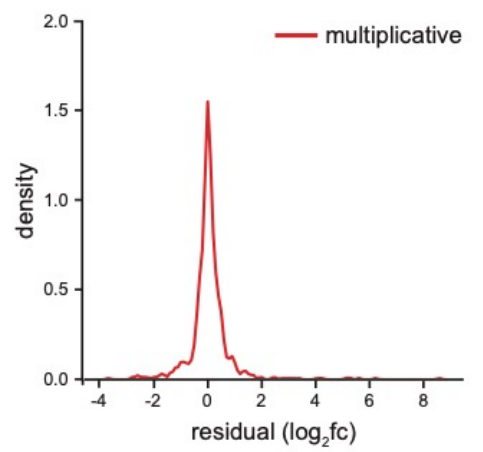

B

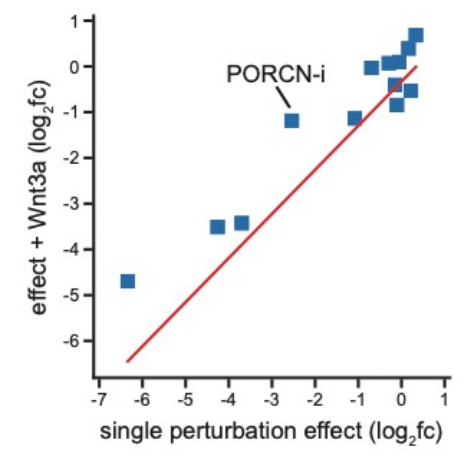

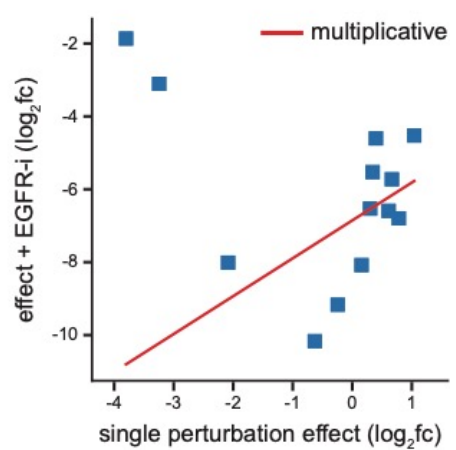

924 Figure 3-Supplement 1. Evaluation of the multiplicative model. (A) Perturbation effects are

925 generally similar to the predictions of the multiplicative model. Distribution of residual between

926 predicted and observed values across all cell-type readouts is shown. (B) Individual perturbations

927 are either predicted by the multiplicative model or diverge significantly. Examples of well-

928 predicted (Wnt3a) and divergent (EGFR-i) perturbations are shown. Effects shown are on \#TA

929 cells. The multiplicative model predicts an interaction between an inhibitor of PORCN, an

930 enzyme required to process epithelial-intrinsic Wnt3a, and Wnt3a treatment (left). 


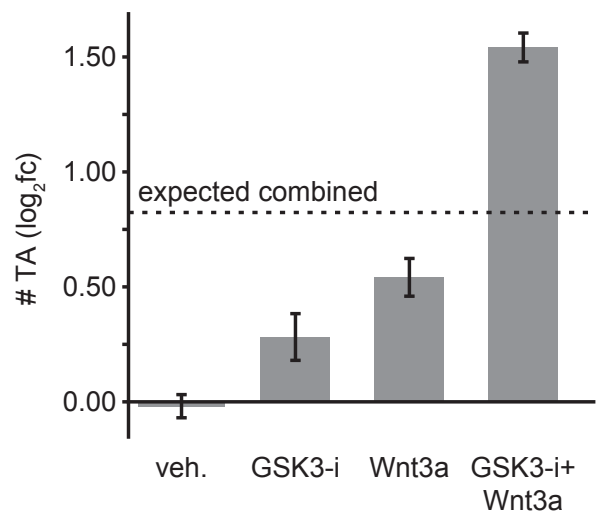

932 Figure 3-Supplement 2. Example of perturbation interaction between Wnt3a and GSK3-i.

933 The combination effect of Wnt3a and GSK3-i is much higher than would be expected under the

934 multiplicative model. This synergism can be explained by the mechanisms of Wnt3a and GSK3-i

935 as both perturbations impact components of the Wnt pathway. 
A

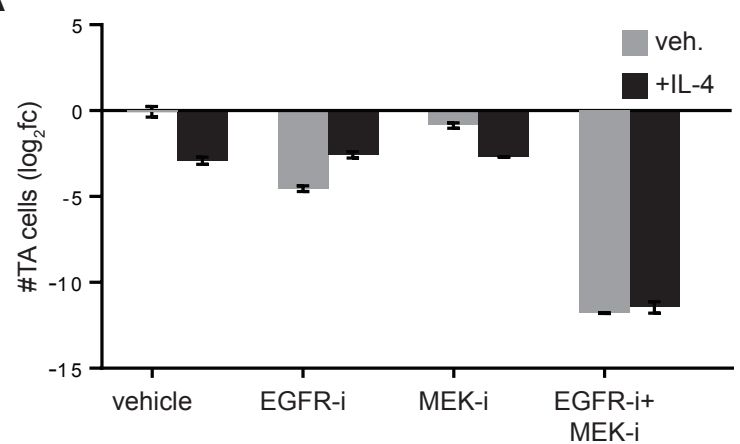

B

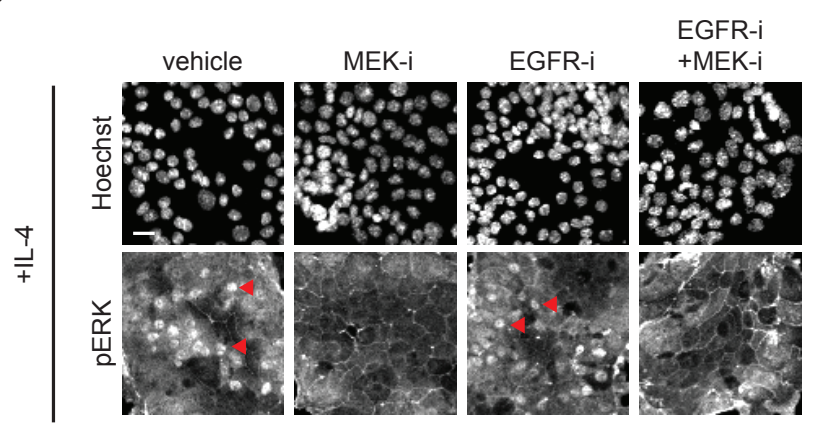

937 Figure 3-Supplement 3. Regulation of MEK-Erk activity by EGFR and IL-4. (A)

938 Antagonistic effect of IL-4 on EGFR-i is dependent on MEK activity. Enteroid monolayers were

939 treated as indicated for 48 hours and the number of TA cells quantified. n=2-6 wells. (B) MEK

940 inhibition reduces Erk activation (nuclear translocation of phospho-Erk) in enteroid monolayers

941 even in the context of IL-4 treatment. Enteroid monolayers were treated with the indicated

942 compounds for $24 \mathrm{hr}$ and then stained for phospho-Erk1/2. Red arrowheads indicate example

943 cells with nuclear phospho-Erk. Scale bar $7.5 \mu \mathrm{m}$. 


\section{A}

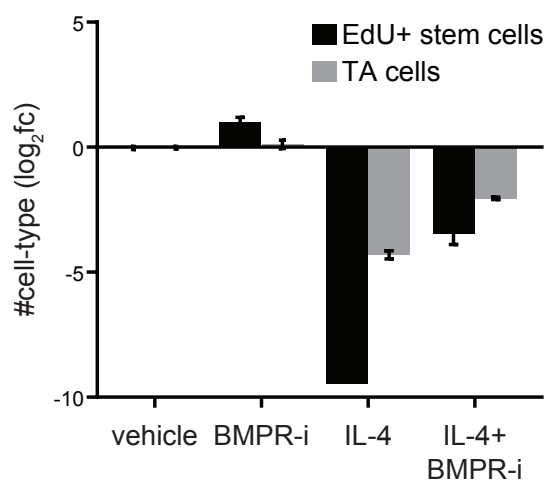

B

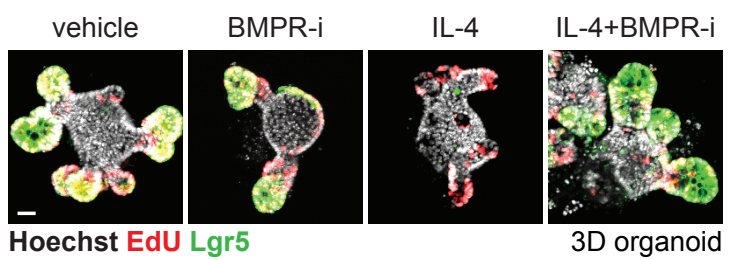

945 Figure 3-Supplement 4. Regulation of BMP signaling by IL-4. (A) BMP receptor inhibition

946 blocks IL-4-induced downregulation of TA cell numbers and stem cell numbers. Enteroid

947 monolayers were treated as indicated for 48 hours and both $\mathrm{EdU}^{+}$stem and TA cell numbers

948 quantified. $\mathrm{n}=2-6$ wells. (B) BMP receptor inhibition blocks IL-4-induced downregulation of

949 proliferation and stemness in 3D organoids. 3D organoids were treated with vehicle or IL-4 in

950 the presence and absence of BMP receptor inhibitor for $48 \mathrm{hrs}$ and then stained for proliferating

951 cells $\left(\mathrm{EdU}^{+}\right)$and stem cells $\left(\mathrm{Lgr}^{+}\right)$. Scale bar $20 \mu \mathrm{m}$. 
A

D
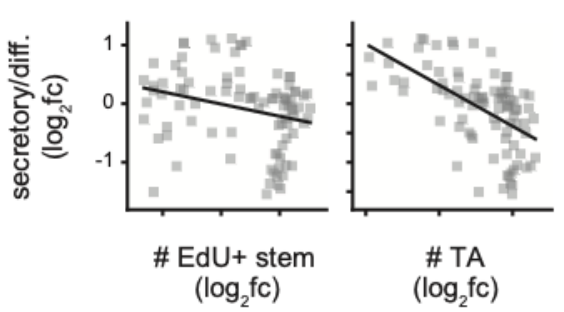

B

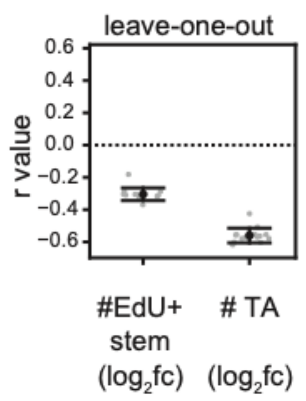

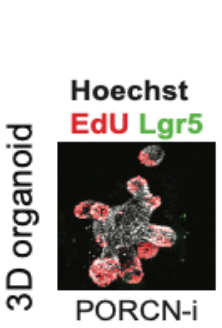
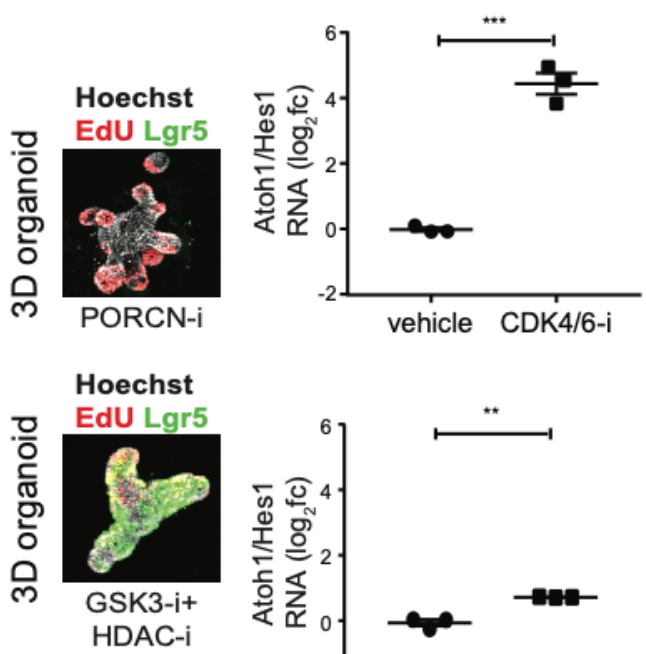

C

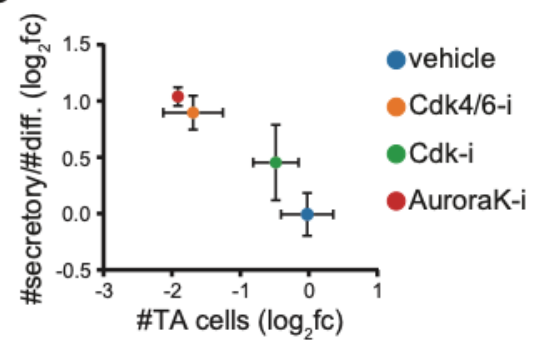

958

959

960

961

962

\section{E}
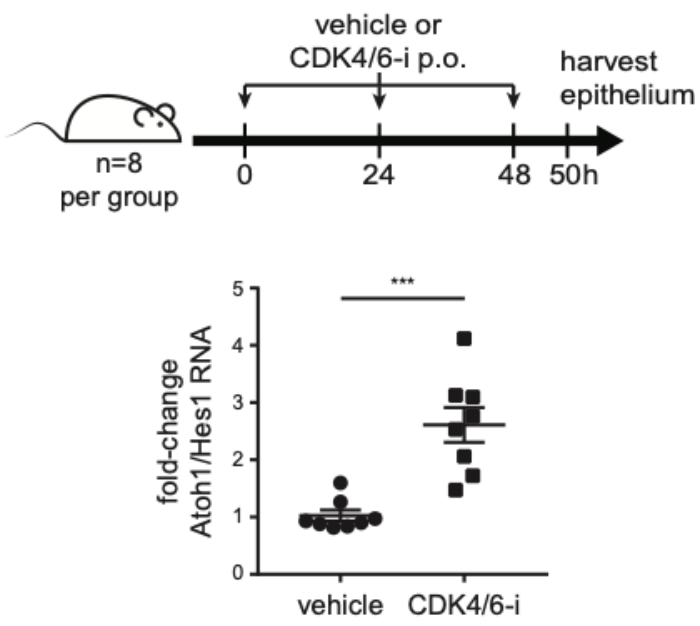

Figure 4. Inhibiting proliferation increases secretory cell prevalence in enteroid

monolayers, in 3D organoids, and in vivo. (A) Numbers of transit-amplifying (TA) cells, but not $\mathrm{EdU}^{+}$stem cells, correlate with secretory cell fractions. Perturbation effects $\left(\log _{2} f \mathrm{c}\right)$ are plotted pairwise for each feature. (B) The TA-secretory correlation is not driven by a specific perturbation. Each of 13 perturbations was sequentially dropped from the dataset and $\mathrm{r}$ value calculated. (C) Inhibiting cell cycle progression increases secretory cell fractions. Enteroids were treated as indicated for 48hrs, after which \#TA cells, and \#secretory/\#differentiated cells were quantified. $\mathrm{n}=3$ wells. (D) TA cells are sufficient to alter secretory fractions in response to cell cycle inhibitors. 3D organoids were perturbed into stem or TA cell-rich states using PORCN-i (TA) or GSK3-i+HDAC-i (stem), respectively. These factors were removed and then a CDK4/6 
963 inhibitor (palbociclib) was applied. The secretory:absorptive ratio was measured at 2 days post-

964 treatment by qRT-PCR for the Atoh1/Hes1 ratio in TA-enriched $(p=0.0002)$ or stem-enriched

965 ( $\mathrm{p}=0.01) 3 \mathrm{D}$ organoids. $\mathrm{n}=3$ wells. (E) Impairing proliferation increases the

966 secretory:absorptive ratio in vivo. Mice were treated with CDK4/6-i (palbociclib) or vehicle

967 every $24 \mathrm{hr}$ for $48 \mathrm{hrs}$. At $50 \mathrm{hrs}$, intestinal crypts were harvested and gene expression was

968 measured by qRT-PCR. CDK4/6-i increases the Atoh1:Hes1 ratio $(\mathrm{p}=0.00005)$. $\mathrm{n}=8$ mice/group.

969 Error bars mean $+/-$ sem. 
A

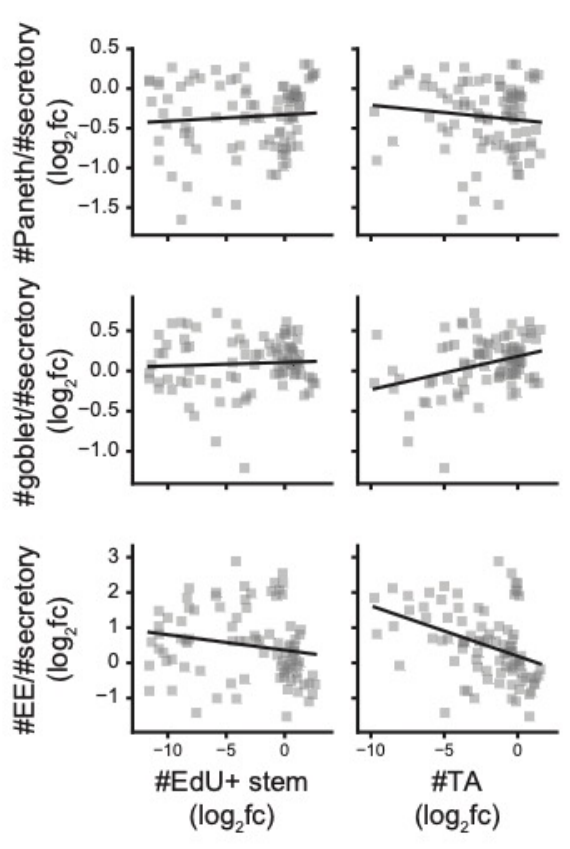

971 Figure 4-Supplement 1. The correlation between TA cell numbers and EE cell prevalence is

972 driven by EGFR-i. (A) Numbers of transit-amplifying (TA) cells correlate with EE cell

973 fractions. Perturbation effects $\left(\log _{2} f \mathrm{f}\right)$ are plotted pairwise for each feature. (B) Each of 13

974 perturbations was sequentially dropped from the dataset and correlation coefficient (r value)

975 calculated. Red arrowhead indicates loss of correlation between \#TA cells and \#EE/\#secretory

976 after dropping EGFR-i.
B
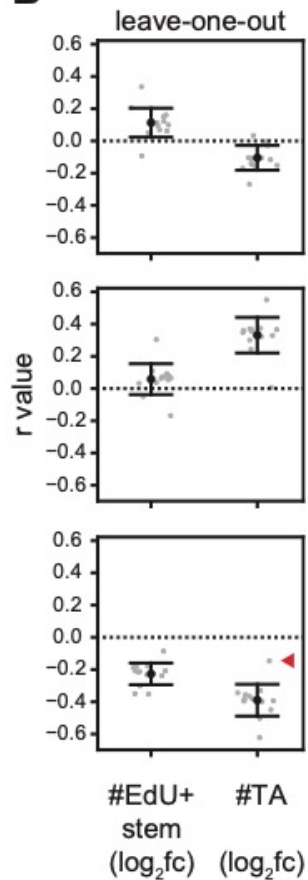


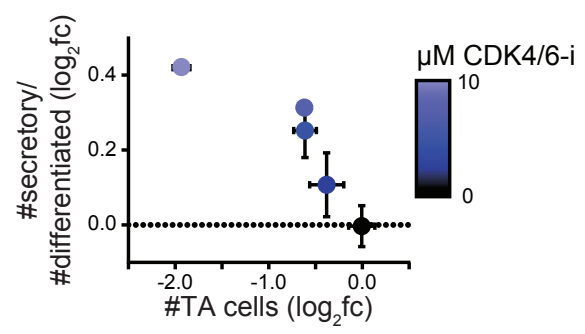

978 Figure 4-Supplement 2. Dose-dependent increase in secretory prevalence upon CDK4/6

979 inhibition. Increasing amounts of CDK4/6 inhibitor were applied (concentrations indicated by

980 color bar) to enteroid monolayers for 48 hours. Changes in the TA cells (\#TA cells $\log _{2} \mathrm{fc}$ ) and

981 secretory cell prevalence amongst differentiated cells (\#secretory/\#differentiated $\left.\log _{2} f c\right)$ were

982 quantified. The color of each point indicates the concentration of CDK4/6 inhibitor applied. $n=3$

983 wells. 


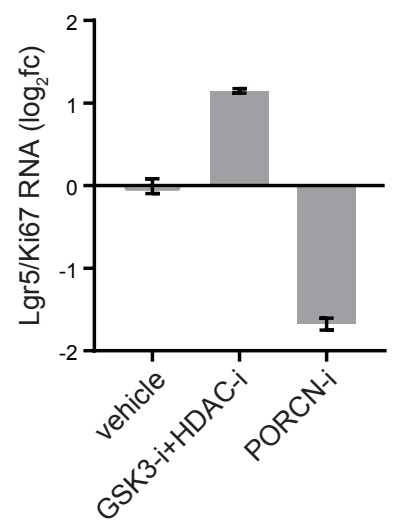

985 Figure 4-Supplement 3. Confirming enrichment of stem versus proliferating cells in 3D

986 organoids treated with GSK3-i+HDAC-i or PORCN-i. 3D organoids were treated with

987 GSK3-i+HDAC-i for 2 days or PORCN-i for 1 day and relative abundance of stem (Lgr5) and

988 proliferating (Ki67) cell RNA was measured by qRT-PCR. GSK3-i+HDAC-i increases stemness

989 relative to proliferation and PORCN-i decreases stemness relative to proliferation. $\mathrm{n}=3$ wells. 
A

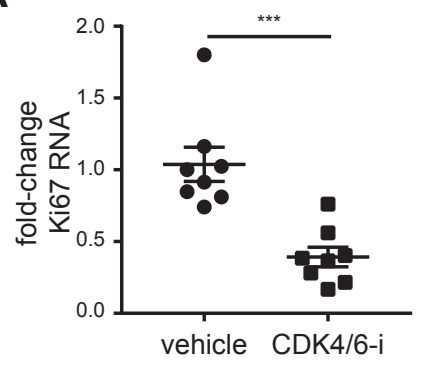

B

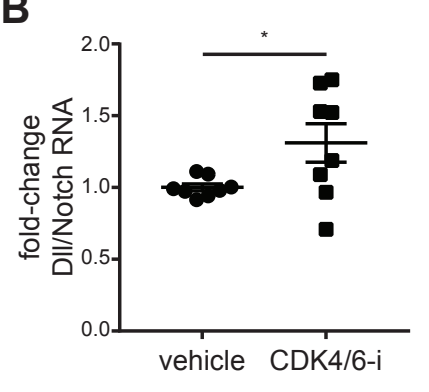

991 Figure 4-Supplement 4. Quantifying changes in proliferation and secretory prevalence in

992 CDK4/6-i-treated mice. Small intestinal epithelial crypts were harvested from mice treated with

993 vehicle or the CDK4/6-i palbociclib. (A) To quantify changes in proliferation, Ki67 RNA was

994 measured by qRT-PCR. CDK4/6-i decreases Ki67 expression ( $p=0.0003)$. (B) To quantify

995 changes in the ratio of secretory:absorptive cell-types, D11 (D111+D114) RNA and Notch

996 (Notch1+Notch2) RNA was measured by qRT-PCR. CDK4/6-i increases the Dll/Notch ratio,

997 indicating an increase in secretory cell-types $(\mathrm{p}=0.039) . \mathrm{n}=8 \mathrm{mice} /$ group. 
A
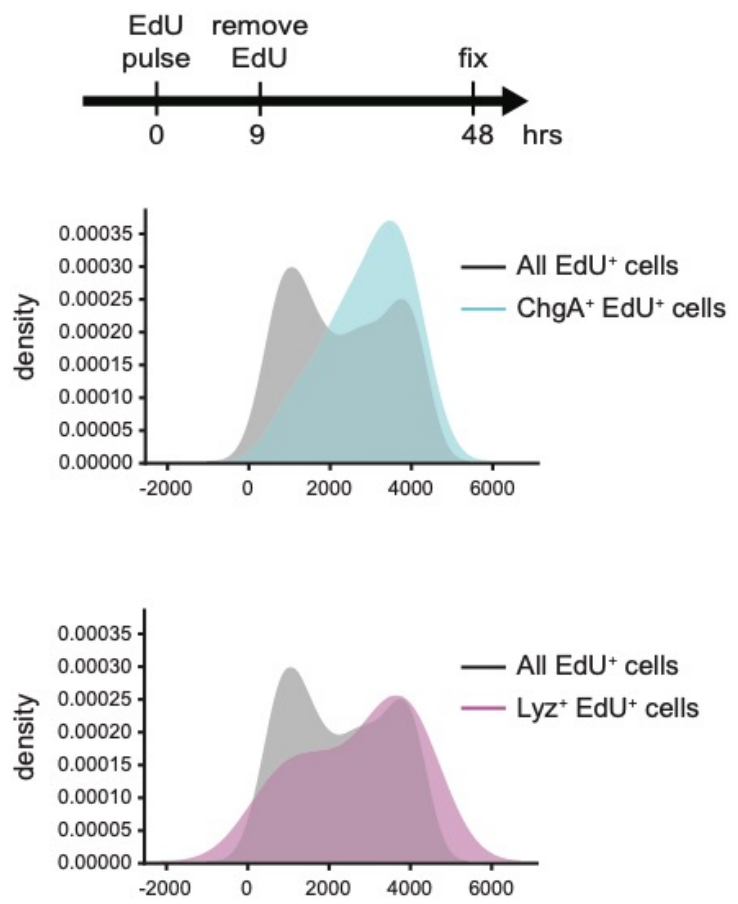

998

999

1000

1001

1002

1003

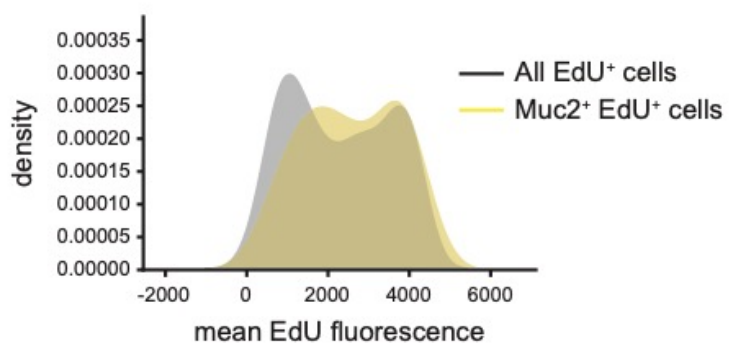

B
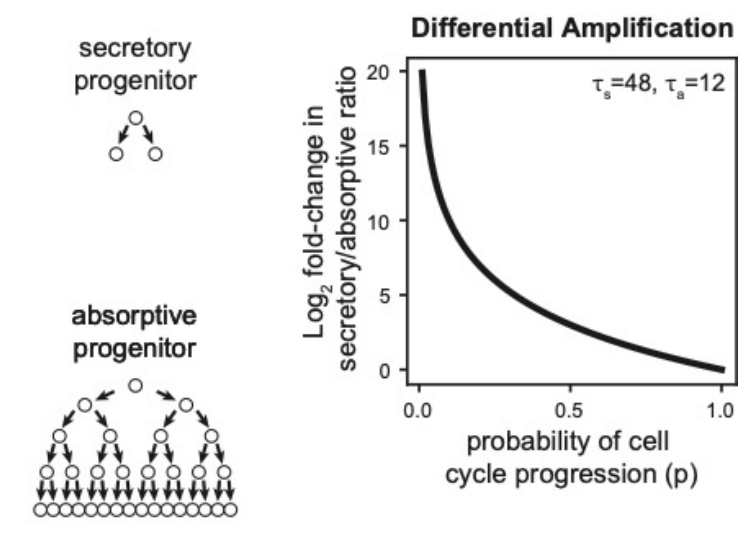

C

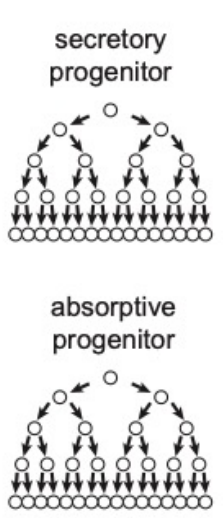

Equal Amplification

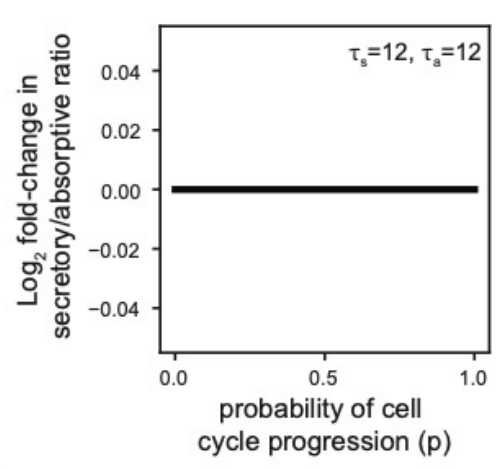

Figure 5. Differential amplification of secretory progenitors connects proliferation with differentiated cell-type composition. (A) Secretory progenitors divide fewer times than other progenitors. Enteroids were pulsed with EdU for 9 hours. After 39 further hours of culture enteroids were fixed and stained. Mean EdU signal intensity was quantified in all EdU ${ }^{+}$cells and in $\mathrm{EdU}^{+}$cells that also stained positive for markers of Paneth (Lyz), goblet (Muc2) and EE

1004 (ChgA) cells. Distribution of EdU intensities is represented as a kde plot. (B) If secretory

1005 progenitors divide fewer times than absorptive progenitors, inhibiting the cell cycle increases the 1006 secretory:absorptive ratio. Exponential growth model parameters are shown where secretory cell 
1007 progenitors divide once $\left(\tau_{\mathrm{s}}=48 \mathrm{hr}\right)$ and absorptive cell progenitors divide four times $\left(\tau_{\mathrm{a}}=12 \mathrm{hr}\right)$

1008 over a $48 \mathrm{hr}$ model time. (C) If secretory progenitors divide the same number of times as

1009 absorptive progenitors, inhibiting the cell cycle will not affect the secretory:absorptive ratio.

1010 Exponential growth model parameters are shown where both secretory and absorptive

1011 progenitors divide four times $\left(\tau_{\mathrm{a}}=\tau_{\mathrm{s}}=12 \mathrm{hr}\right)$. For other model parameterizations see Figure 5-

1012 Supplement 1. 
A

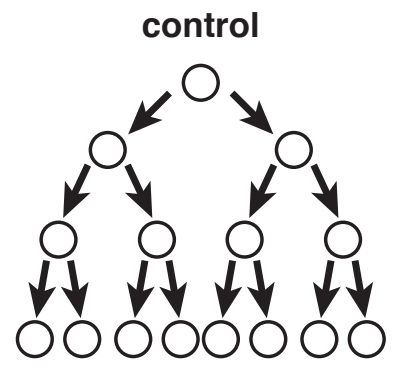

$p=1$

\section{perturbation}

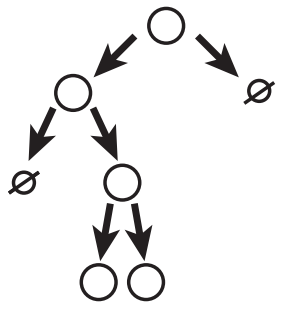

$\mathrm{p}<1$

p: probability of cell cycle progression

1 - p: probability of quiescence

B Secretory progenitor cell cycle length $\tau_{a}(h)$
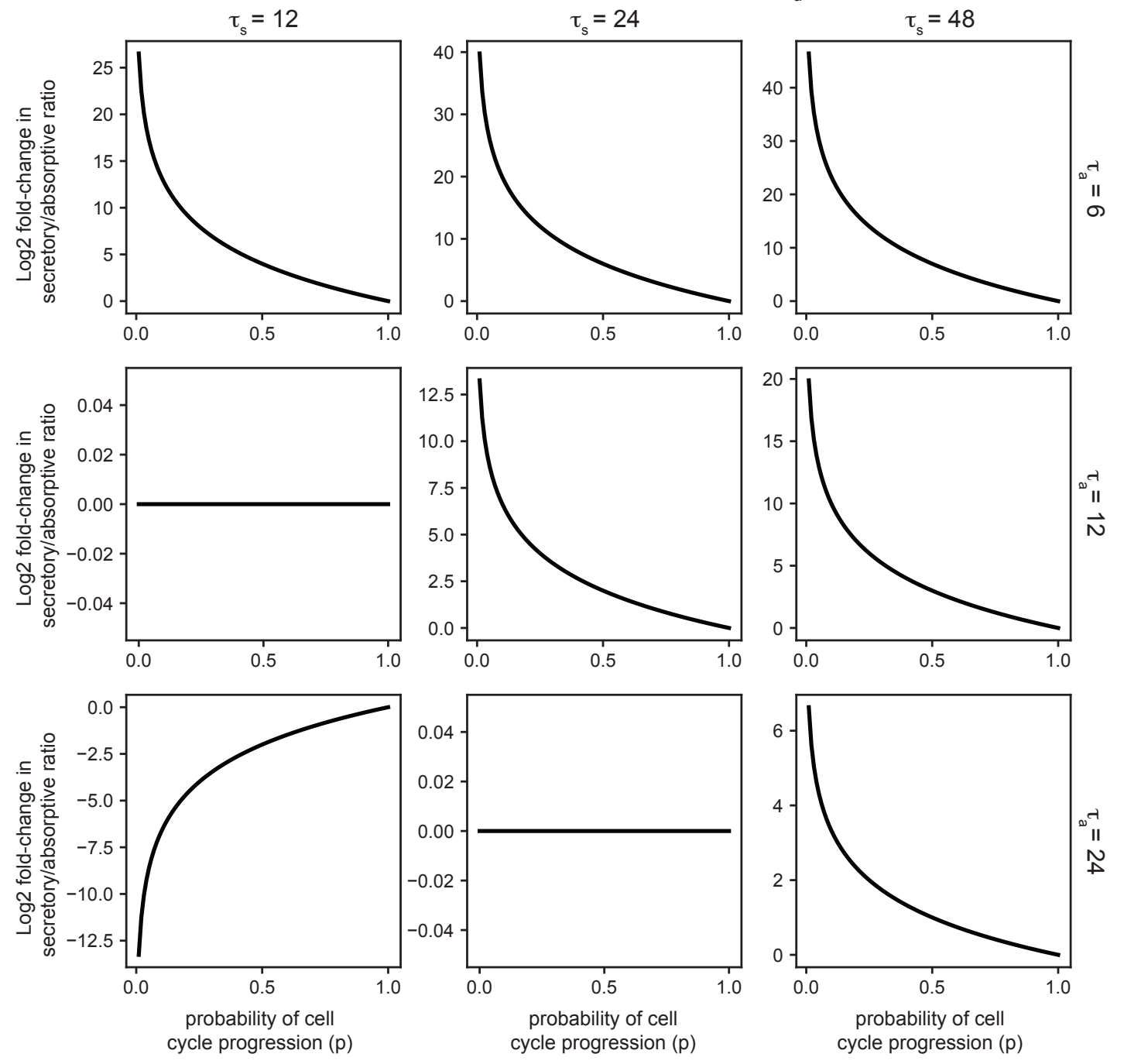

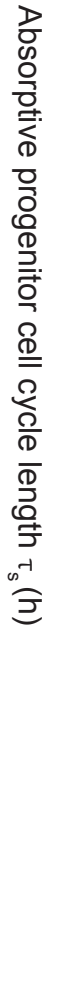


1014 Figure 5-Supplement 1. Cell cycle modulators affect the secretory:absorptive ratio due to

1015 differential amplification of secretory and absorptive progenitors. (A) Diagram of the effect

1016 of altering $\mathrm{p}$, a parameter setting the probability of progenitor cell cycle progression. (B)

1017 Exponential growth model supports the hypothesis that secretory progenitors divide fewer times

1018 than absorptive progenitors. The parameters $\tau_{\mathrm{a}}$ and $\tau_{\mathrm{s}}$ describe how often secretory and

1019 absorptive progenitors divide. Only when secretory progenitors have longer cell cycle lengths

$1020\left(\tau_{\mathrm{s}}>\tau_{\mathrm{a}}\right)$ and thus undergo fewer divisions than absorptive progenitors during the 48-hour

1021 simulation period does decreasing the probability of cell cycle progression increase the

1022 secretory:absorptive ratio, and vice versa. 
bioRxiv preprint doi: https://doi.org/10.1101/840371; this version posted March 12, 2020. The copyright holder for this preprint (which was not certified by peer review) is the author/funder, who has granted bioRxiv a license to display the preprint in perpetuity. It is made available under aCC-BY-NC-ND 4.0 International license.

1023 Tables

\begin{tabular}{|c|c|c|c|c|}
\hline Cell-type & Marker & Precision & Recall & F1 Score \\
\hline nuclei & Hoechst & 0.9965 & 0.9936 & 0.9951 \\
\hline goblet cells & Muc2 & 1 & 0.8998 & 0.9473 \\
\hline EE cells & ChgA & 0.8551 & 0.9248 & 0.8886 \\
\hline Paneth cells & Lyz & 0.9018 & 0.9642 & 0.9319 \\
\hline EdU+cells & EdU & 1 & 0.9557 & 0.9774 \\
\hline crypt regions & Lgr5-GFP & 0.9816 & 0.9877 & 0.9846 \\
\hline stem cells & Lgr5-GFP & 0.9724 & 0.9756 & 0.9740 \\
\hline Lgr5+/Dclk1+cells & Lgr5-GFP & 0.8208 & 0.9087 & 0.8625 \\
\hline
\end{tabular}

1024 Table 1. Evaluation of the performance of cell-type identification algorithms. 
bioRxiv preprint doi: https://doi.org/10.1101/840371. this version posted March 12, 2020. The copyright holder for this preprint (which was not certified by peer review) is the author/funder, who has granted bioRxiv a license to display the preprint in perpetuity. It is made available under aCC-BY-NC-ND 4.0 International license.

\begin{tabular}{|c|c|c|}
\hline Cell Type & In Vivo (\%) & Enteroid Monolayer (\%) \\
\hline Paneth & $\begin{array}{c}7.5 \% \\
\text { of crypt cells(Cheng \& Leblond, } \\
1974 a)\end{array}$ & $\begin{array}{c}3.1 \% \\
\text { of all cells }\end{array}$ \\
\hline Goblet & 4-6(Cheng \& Leblond, 1974a) & 3.8 \\
\hline EE & 0.6(Cheng \& Leblond, 1974a) & 0.4 \\
\hline
\end{tabular}

1025 Table 2. Comparison of enteroid monolayer cell-type composition with literature reports of 1026 small intestine cell-type composition. 
bioRxiv preprint doi: https://doi org/10.1101/840371; this version posted March 12, 2020. The copyright holder for this preprint (which was not certified by peer review) is the author/funder, who has granted bioRxiv a license to display the preprint in perpetuity. It is made available under aCC-BY-NC-ND 4.0 International license.

\begin{tabular}{|c|c|c|c|c|c|c|}
\hline Pathway & Perturbation & Target & Designation & $\begin{array}{c}\text { Pathway } \\
\text { Effect }\end{array}$ & Published Effect(s) on Intestinal Epithelium & Dose Ref. \\
\hline EGFR & erlotinib & EGFR & EGFR-i & inhibit & $\begin{array}{l}\text { Reduced proliferation, increased EE cell } \\
\text { (Basak et al., 2017a) }\end{array}$ & (Basak et al., 2017a) \\
\hline \multirow[t]{3}{*}{ Wnt } & Wnt3a & Frizzled & Wnt3a & activate & $\begin{array}{l}\text { Increased proliferation } \\
\text { (Clevers, 2013) }\end{array}$ & (Thorne et al., 2018) \\
\hline & IWP-2 & PORCN & PORCN-i & inhibit & $\begin{array}{l}\text { Decreased proliferation, stem cells, Paneth cells } \\
\text { (Basak et al., 2017a; Farin et al., 2016; Rodríguez- } \\
\text { Colman et al., 2017; van Es et al., 2005) }\end{array}$ & (Yin et al., 2014b) \\
\hline & CHIR99021 & GSK3 & GSK3-i & activate & $\begin{array}{l}\text { Increased proliferation, stem cells } \\
\text { (Yin et al., 2014b) }\end{array}$ & (Yin et al., 2014b) \\
\hline \multirow[t]{2}{*}{ BMP } & BMP4 & BMPR & BMP4 & activate & $\begin{array}{l}\text { Decreased proliferation and stem cells } \\
\qquad \text { (Qi et al., 2017) }\end{array}$ & (Thorne et al., 2018) \\
\hline & LDN-193189 & ALK $2 / 3$ & BMPR-i & inhibit & $\begin{array}{l}\text { Increased proliferation and stem cells } \\
\qquad \text { (Li et al., 2018) }\end{array}$ & (Thorne et al., 2018) \\
\hline \multirow[t]{2}{*}{ TGF- $\beta$} & TGF- $\beta$ & TGF- $\beta R$ & TGF- $\beta$ & activate & $\begin{array}{l}\text { Important for differentiation in vivo } \\
\text { (Flentjar et al., 2007; Li et al., 2018; van der Flier } \\
\text { et al., 2009) }\end{array}$ & (Han et al., 2014) \\
\hline & EW-7197 & ALK4/5 & TGF- $\beta R-i$ & inhibit & $?$ & (Hong et al., 2017) \\
\hline Notch & DAPT & $\gamma$-secretase & Notch-i & inhibit & $\begin{array}{l}\text { Increased secretory cell-types } \\
\text { (VanDussen et al., 2012) }\end{array}$ & (Yin et al., 2014b) \\
\hline \multirow[t]{2}{*}{ IL-4-JAK } & IL-4 & IL-4R & IL-4 & activate & $\begin{array}{l}\text { Increased goblet cells } \\
\text { (von Moltke et al., 2015) }\end{array}$ & (von Moltke et al., 2015) \\
\hline & baricitinib & JAK1/2 & JAK $1 / 2-\mathrm{i}$ & inhibit & $\begin{array}{l}\text { Altered stem cell numbers } \\
\text { (Batlle et al., 2002; Richmond et al., 2018b) }\end{array}$ & (Dames et al., 2015) \\
\hline HDAC & valproic acid & HDAC1/2 & HDAC-i & inhibit & $\begin{array}{l}\text { Increased stem cells } \\
\text { (von Moltke et al., 2015; Yin et al., 2014b) }\end{array}$ & (Yin et al., 2014b) \\
\hline $\begin{array}{l}\text { p38 } \\
\text { MAPK }\end{array}$ & SB202190 & p38 MAPK & p38 MAPK-i & inhibit & $\begin{array}{l}\text { Increased proliferation } \\
\text { (M. Houde et al., 2001; Sato et al., 2011) }\end{array}$ & (Sato et al., 2011) \\
\hline
\end{tabular}

1027 Table 3. Selection of cell-type perturbations for study. For each perturbation, the specific

1028 pathway and target are indicated, as is the expected effect on the pathway and tissue. Designation

1029 is the code with which the perturbation is referred to in figures and text. 
bioRxiv preprint doi: https://doi.org/10.1101/840371; this version posted March 12, 2020. The copyright holder for this preprint (which was not certified by peer review) is the author/funder, who has granted bioRxiv a license to display the preprint in perpetuity. It is made available under aCC-BY-NC-ND 4.0 International license.

\begin{tabular}{|c|c|c|c|c|}
\hline & \multicolumn{2}{|c|}{ Downregulating } & \multicolumn{2}{|c|}{ Upregulating } \\
\hline & Perturbation & $\log _{2} f \mathrm{c}$ & Perturbation & $\log _{2} f \mathrm{c}$ \\
\hline \multirow{3}{*}{ EdU+ stem number } & BMP4 + JAK1/2-i & -11.380 & GSK3-i + p38 MAPK-i & 2.602 \\
\hline & BMP4 & -11.080 & GSK3-i + JAK1/2-i & 2.405 \\
\hline & BMP4 + Wnt3a & -10.380 & BMPR-i + p38 MAPK-i & 2.363 \\
\hline \multirow{3}{*}{ TA number } & EGFR-i + HDAC-i & -9.476 & GSK3-i + Wnt3a & 1.541 \\
\hline & IL-4 + PORCN-i & -9.437 & GSK3-i + JAK1/2-i & 1.415 \\
\hline & EGFR-i + TGF- $\beta R-i$ & -8.512 & BMPR-i + Wnt3a & 1.240 \\
\hline \multirow{3}{*}{$\begin{array}{c}\text { Secretory fraction } \\
\text { (of differentiated cells) }\end{array}$} & TGF $\beta+$ Wnt3a & -1.544 & GSK3-i + EGFR-i & 1.109 \\
\hline & $\mathrm{BMP4}+\mathrm{TGF} \beta$ & -1.509 & EGFR-i + BMPR-i & 1.096 \\
\hline & TGF $\beta+$ HDAC-i & -1.452 & EGFR-i + JAK1/2-i & 1.062 \\
\hline \multirow{3}{*}{$\begin{array}{l}\text { Paneth fraction } \\
\text { (of secretory cells) }\end{array}$} & $\mathrm{IL}-4+\mathrm{TGF}-\beta$ & -1.651 & $B M P R-i+H D A C-i$ & 0.307 \\
\hline & PORCN-i + TGF- $\beta$ & -1.466 & GSK3-i + HDAC-i & 0.305 \\
\hline & IL-4 + p38 MAPK-i & -1.417 & EGFR-i + TGF- $\beta$ & 0.270 \\
\hline \multirow{3}{*}{$\begin{array}{l}\text { Goblet fraction } \\
\text { (of secretory cells) }\end{array}$} & EGFR-i + TGF- $\beta$ & -1.209 & IL-4 + p38 MAPK-i & 0.724 \\
\hline & Notch-i + EGFR-i & -0.880 & TGF- $\beta R-i+W n t 3 a$ & 0.611 \\
\hline & EGFR-i + PORCN-i & -0.558 & IL-4 + TGF- $\beta$ & 0.604 \\
\hline \multirow{3}{*}{$\begin{array}{c}\text { EE fraction } \\
\text { (of secretory cells) }\end{array}$} & TGF- $\beta R-i+W n t 3 a$ & -1.525 & PORCN-i + TGF- $\beta$ & 2.885 \\
\hline & IL-4 + HDAC-i & -1.419 & Notch-i + TGF- $\beta$ & 2.542 \\
\hline & GSK3-i + HDAC-i & -1.098 & TGF- $\beta$ & 2.282 \\
\hline
\end{tabular}

Table 4. Top perturbations in modulating cell-type composition. 